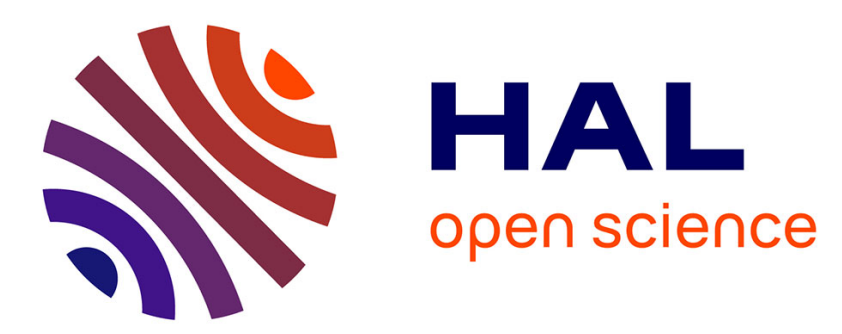

\title{
Contrasting networks and entanglements in uranyl ion complexes with adipic and trans, trans-Muconic acids
}

Pierre Thuéry, Jack Harrowfield

\section{To cite this version:}

Pierre Thuéry, Jack Harrowfield. Contrasting networks and entanglements in uranyl ion complexes with adipic and trans,trans-Muconic acids. Inorganic Chemistry, 2022, 61 (6), pp.2790-2803. 10.1021/acs.inorgchem.1c03168 . cea-03549299

\section{HAL Id: cea-03549299 https://hal-cea.archives-ouvertes.fr/cea-03549299}

Submitted on 31 Jan 2022

HAL is a multi-disciplinary open access archive for the deposit and dissemination of scientific research documents, whether they are published or not. The documents may come from teaching and research institutions in France or abroad, or from public or private research centers.
L'archive ouverte pluridisciplinaire HAL, est destinée au dépôt et à la diffusion de documents scientifiques de niveau recherche, publiés ou non, émanant des établissements d'enseignement et de recherche français ou étrangers, des laboratoires publics ou privés. 


\title{
Contrasting Networks and Entanglements in Uranyl Ion Complexes with Adipic and trans,trans-Muconic Acids
}

\author{
Pierre Thuéry*,† and Jack Harrowfield ${ }^{*, \dagger}$ \\ †Université Paris-Saclay, CEA, CNRS, NIMBE, 91191 Gif-sur-Yvette, France \\ †Université de Strasbourg, ISIS, 8 allée Gaspard Monge, 67083 Strasbourg, France
}

\begin{abstract}
Adipic (hexane-1,6-dicarboxylic, adpH ${ }_{2}$ ) and trans, trans-muconic (trans, trans-hexa-2,4-diene-1,6dicarboxylic, $\mathrm{mucH}_{2}$ ) acids have been reacted with uranyl cations under solvo-hydrothermal conditions, yielding nine homo- or heterometallic complexes displaying in their crystal structure the effects of the different flexibility of the ligands. The complexes $\left[\mathrm{PPh}_{4}\right]_{2}\left[\left(\mathrm{UO}_{2}\right)_{2}(\mathrm{adp})_{3}\right](\mathbf{1})$ and $\left[\mathrm{Ni}(\mathrm{bipy})_{3}\right]\left[\left(\mathrm{UO}_{2}\right)_{2}(\mathrm{muc})_{3}\right] \cdot 5 \mathrm{H}_{2} \mathrm{O}(\mathbf{2})$, where bipy is 2,2'-bipyridine, crystallize as diperiodic networks with hcb topology, the layers being strongly puckered or quasiplanar, respectively. Whereas $\left[\left(\mathrm{UO}_{2}\right)_{2}(\mathrm{adp})_{3} \mathrm{Ni}(\right.$ cyclam $\left.)\right] \cdot 2 \mathrm{H}_{2} \mathrm{O} \quad(\mathbf{3})$, where cyclam is $1,4,8,11-$ tetraazacyclotetradecane, crystallizes as a diperiodic network, $\left[\left(\mathrm{UO}_{2}\right)_{2}(\text { muc })_{3} \mathrm{Ni}(\mathrm{cyclam})\right] \cdot 2 \mathrm{H}_{2} \mathrm{O}(4)$, is a triperiodic framework in which the $\mathrm{Ni}^{\mathrm{II}}$ cations are introduced as pillars within a uranyl-muc ${ }^{2-}$ framework with mog topology. $\left[\mathrm{UO}_{2}(\operatorname{adp})(\mathrm{HCOO})_{2} \mathrm{Cu}\left(R, S-\mathrm{Me}_{6}\right.\right.$ cyclam $\left.)\right] \cdot 2 \mathrm{H}_{2} \mathrm{O} \quad(5), \quad$ where $\quad R, S-\mathrm{Me}_{6}$ cyclam is $7(R), 14(S)-5,5,7,12,12,14-$ hexamethylcyclam, is a diperiodic assembly with sql topology, and it crystallizes together with $\left[\mathrm{H}_{2} \mathrm{NMe}_{2}\right]_{2}\left[\left(\mathrm{UO}_{2}\right)_{2}(\mathrm{adp})_{3}\right](\mathbf{6})$, a highly corrugated heb network with a square-wave profile, which displays threefold parallel interpenetration. In contrast, $\left[\left(\mathrm{UO}_{2}\right)_{3}(\mathrm{muc})_{2}(\mathrm{O})_{2} \mathrm{Cu}\left(R, S-\mathrm{Me}_{6}\right.\right.$ cyclam $\left.)\right](7)$ is a diperiodic assembly containing hexanuclear, $\mu_{3}$-oxido-bridged secondary building units which are the nodes of a network with hxl topology. The two related complexes $\left[\mathrm{PPh}_{3} \mathrm{Me}_{2}\left[\left(\mathrm{UO}_{2}\right)_{2}(\operatorname{adp})_{3}\right] \cdot 4 \mathrm{H}_{2} \mathrm{O}(\mathbf{8})\right.$ and $\left[\mathrm{PPh}_{3} \mathrm{Me}\right]_{2}\left[\left(\mathrm{UO}_{2}\right)_{2}(\mathrm{muc})_{3}\right] \cdot \mathrm{H}_{2} \mathrm{O}(\mathbf{9})$ crystallize as hcb networks, but their different shapes, undulated or quasi-planar, respectively, result in different entanglements, twofold parallel interpenetration in $\mathbf{8}$ and twofold inclined 2D $\rightarrow 3 \mathrm{D}$ polycatenation in 9.
\end{abstract}




\section{INTRODUCTION}

Interpenetration or polycatenation phenomena, commonly encountered in crystal structures of coordination polymers, are most intriguing from both topological ${ }^{1-6}$ and practical $^{7-11}$ viewpoints. While various factors have been identified as favoring their occurrence, its prediction in any given system remains quite uncertain..$^{5,7,9}$ To describe the structure of a coordination polymer as involving entanglement, it is necessary to identify at least two polymer components which are united in the crystal only through what are conventionally termed "noncovalent" interactions. The monomer components of these polymers are linked to one another through coordinate bonds, in most cases being formed by labile metal ions, so that in solution the polymer can readily undergo dissociation and therefore can be considered "dynamic". ${ }^{12}$ This means that the crystallization of an entangled coordination polymer can be considered as a molecular analogue of 3D printing where appropriate spatial location of small aggregates leads directly to the entangled structure through the operation of a variety of interactions, both weak and strong. ${ }^{13}$ One of the nets has to fit in the voids defined by the other, so that self-dual nets may have a particular tendency to get entangled. ${ }^{14}$

Rigid ligands in which two donor groups are held in a divergent, widely spaced array appear to favor entanglement ${ }^{7}$ but, in the particular case of uranyl-organic coordination polymers or frameworks, ${ }^{15-20}$ one of the first examples reported involved adipic acid $(\operatorname{adpH})_{2},{ }^{21}$ a ligand notable for its flexibility. In this complex, [UO 2 (adp)(4,4'-bipy)], in which the 4,4'bipyridine coligand introduces a degree of rigidity, three diperiodic networks are involved in inclined polycatenation to give a triperiodic structure (we use here the terms interpenetration and polycatenation as indicating that the periodicity of the entangled species is the same or higher, respectively, than that of the components ${ }^{3}$ ). Structural studies of uranyl ion complexes with acyclic, aliphatic $\alpha, \omega$-dicarboxylic acids $\left(\mathrm{H}_{2} \mathrm{Cn}\right)$, of which adipic acid is a member $(n=$ 
6), have been extensive, with as many as a hundred structures reported in the Cambridge Structural Database (CSD, Version 5.42), ${ }^{22,23}$ for $3 \leq n \leq 15$, and have led to the characterization of species, such as triperiodic frameworks ${ }^{24}$ or binuclear helicates, ${ }^{25}$ defining a remarkable variety of forms dependent upon, for example, the uranyl/carboxylate ratio, the dicarboxylate chain length, the presence of co-ligands or counterions. Within this variety, however, observations of entanglement are quite rare, with, in addition to the inclined polycatenated adipate species cited above, parallel $2 \mathrm{D} \rightarrow 3 \mathrm{D}$ polycatenation for $n=7,{ }^{26,27}$ and parallel $2 \mathrm{D} \rightarrow$ $2 \mathrm{D}$ interpenetration for $n=13^{28}$ having been reported. Notwithstanding the number of entangled systems presently known in uranyl chemistry, often involving rigid carboxylate ligands, ${ }^{29-35}$ prediction of the occurrence of this phenomenon even in this particular area remains highly uncertain.

We have now extended some of our earlier work on uranyl ion complexes of aliphatic $\alpha, \omega$-dicarboxylates in the particular case of adipate, and added for comparison complexes with trans,trans-muconate (trans,trans-hexa-2,4-diene-1,6-dicarboxylate, muc ${ }^{2-}$ ), an unsaturated relative of adipate, of similar length but more rigid, for which no actinide complex has been crystallographically characterized up to now and which might be expected to show some differences in its coordination due to the conformational restrictions introduced by the double bonds. Nine anionic complexes have been synthesized, which include as different structuredirecting cations $\mathrm{H}_{2} \mathrm{NMe}_{2}{ }^{+}, \mathrm{PPh}_{4}{ }^{+}, \mathrm{PPh}_{3} \mathrm{Me}^{+},\left[\mathrm{Ni}(\text { bipy })_{3}\right]^{2+}$, $[\mathrm{Ni}(\text { cyclam })]^{2+}$, and $[\mathrm{Cu}(R, S-$ $\mathrm{Me}_{6}$ cyclam $\left.)\right]^{2+}\left(\right.$ bipy $=2,2^{\prime}$-bipyridine; cyclam = 1,4,8,11-tetraazacyclotetradecane; $R, S$ $\mathrm{Me}_{6}$ cyclam (meso isomer) $=7(R), 14(S)-5,5,7,12,12,14$-hexamethylcyclam). Crystallographic characterization has revealed three examples of entanglement in this series, either twofold or threefold $2 \mathrm{D} \rightarrow 2 \mathrm{D}$ interpenetration or inclined $2 \mathrm{D} \rightarrow 3 \mathrm{D}$ polycatenation, which offer some insights as to the role of ligand geometry. 


\section{EXPERIMENTAL SECTION}

Syntheses. Caution! Uranium is a radioactive and chemically toxic element, and uranium-containing samples must be handled with suitable care and protection. Small quantities of reagents and solvents were employed to minimize any potential hazards arising both from the presence of uranium and the use of pressurized vessels for the syntheses.

$\left[\mathrm{UO}_{2}\left(\mathrm{NO}_{3}\right)_{2}\left(\mathrm{H}_{2} \mathrm{O}\right)_{2}\right] \cdot 4 \mathrm{H}_{2} \mathrm{O}(\mathrm{RP}$ Normapur, $99 \%)$ and $\mathrm{Ni}\left(\mathrm{NO}_{3}\right)_{2} \cdot 6 \mathrm{H}_{2} \mathrm{O}$ were purchased from Prolabo. The carboxylic acids were from Aldrich, and 2,2'-bipyridine was from Fluka. $\left[\mathrm{Ni}(\right.$ cyclam $\left.)\left(\mathrm{NO}_{3}\right)_{2}\right]$ and $\left[\mathrm{Cu}\left(R, S-\mathrm{Me}_{6}\right.\right.$ cyclam $\left.)\left(\mathrm{NO}_{3}\right)_{2}\right]$ were synthesized as previously described. ${ }^{27,36}$ Elemental analyses were performed by MEDAC Ltd. For all syntheses, the mixtures in demineralized water/organic solvent were placed in $10 \mathrm{~mL}$ tightly closed glass vessels and heated at $140{ }^{\circ} \mathrm{C}$ under autogenous pressure. The crystals characterized were those deposited under the reaction conditions and not from subsequent cooling and depressurization.

$\left[P P h_{4}\right]_{2}\left[\left(\mathrm{UO}_{2}\right)_{2}(a d p)_{3}\right](\mathbf{1})$. Adipic acid $(15 \mathrm{mg}, 0.10 \mathrm{mmol}),\left[\mathrm{UO}_{2}\left(\mathrm{NO}_{3}\right)_{2}\left(\mathrm{H}_{2} \mathrm{O}\right)_{2}\right] \cdot 4 \mathrm{H}_{2} \mathrm{O}$ (35 mg, $0.07 \mathrm{mmol})$, and $\mathrm{PPh}_{4} \mathrm{Br}(42 \mathrm{mg}, 0.10 \mathrm{mmol})$ were dissolved in water $(0.6 \mathrm{~mL})$ and $\mathrm{N}$ methyl-2-pyrrolidone (NMP, $0.2 \mathrm{~mL}$ ). Yellow crystals of complex 1 were obtained within three weeks (20 mg, 35\% yield based on U). Anal. Calcd for $\mathrm{C}_{66} \mathrm{H}_{64} \mathrm{O}_{16} \mathrm{P}_{2} \mathrm{U}_{2}: \mathrm{C}, 48.01 ; \mathrm{H}, 3.91$. Found: C, 47.40; H, 3.77\%.

$\left[\mathrm{Ni}(\text { bipy })_{3}\right]\left[\left(\mathrm{UO}_{2}\right)_{2}(\mathrm{muc})_{3}\right] \cdot 5 \mathrm{H}_{2} \mathrm{O}$ (2). trans,trans-Muconic acid $(14 \mathrm{mg}, 0.10 \mathrm{mmol})$, $\left[\mathrm{UO}_{2}\left(\mathrm{NO}_{3}\right)_{2}\left(\mathrm{H}_{2} \mathrm{O}\right)_{2}\right] \cdot 4 \mathrm{H}_{2} \mathrm{O}(35 \mathrm{mg}, 0.07 \mathrm{mmol}), \mathrm{Ni}\left(\mathrm{NO}_{3}\right)_{2} \cdot 6 \mathrm{H}_{2} \mathrm{O}(15 \mathrm{mg}, 0.05 \mathrm{mmol})$, and 2,2'bipyridine (bipy, $24 \mathrm{mg}, 0.15 \mathrm{mmol})$ were dissolved in water $(0.8 \mathrm{~mL})$ and $N, N$ dimethylformamide (DMF, $0.2 \mathrm{~mL}$ ). A small quantity of yellow-orange crystals of complex 2 was obtained within three days, mixed with a few yellow crystals of $\left[\mathrm{H}_{2} \mathrm{NMe}_{2}\right]_{2}\left[\left(\mathrm{UO}_{2}\right)_{2}(\mathrm{muc})_{3}\right] \cdot x \mathrm{H}_{2} \mathrm{O}$, which were of insufficient quality for structure refinement, only a rough structural model showing the nature of the compound having been determined. 
$\left[\left(\mathrm{UO}_{2}\right)_{2}(\mathrm{adp})_{3} \mathrm{Ni}(\mathrm{cyclam})\right] \cdot 2 \mathrm{H}_{2} \mathrm{O} \quad$ (3). Adipic acid (15 mg, $\left.0.10 \mathrm{mmol}\right)$, $\left[\mathrm{UO}_{2}\left(\mathrm{NO}_{3}\right)_{2}\left(\mathrm{H}_{2} \mathrm{O}\right)_{2}\right] \cdot 4 \mathrm{H}_{2} \mathrm{O}(35 \mathrm{mg}, 0.07 \mathrm{mmol})$, and $\left[\mathrm{Ni}(\right.$ cyclam $\left.)\left(\mathrm{NO}_{3}\right)_{2}\right](20 \mathrm{mg}, 0.05 \mathrm{mmol})$ were dissolved in water $(0.8 \mathrm{~mL})$ and DMF $(0.2 \mathrm{~mL})$. Yellow crystals of complex 3 were obtained within three days ( $25 \mathrm{mg}$, $56 \%$ yield based on $\mathrm{U}$ ). Anal. Calcd for $\mathrm{C}_{28} \mathrm{H}_{52} \mathrm{~N}_{4} \mathrm{NiO}_{18} \mathrm{U}_{2}$ : C, 26.53; H, 4.13; N, 4.42. Found: C, 26.34; H, 3.99; N, 4.52\%.

$\left[\left(\mathrm{UO}_{2}\right)_{2}(\mathrm{muc})_{3} \mathrm{Ni}(\mathrm{cyclam})\right] \cdot 2 \mathrm{H}_{2} \mathrm{O}$ (4). trans,trans-Muconic acid (14 mg, $\left.0.10 \mathrm{mmol}\right)$, $\left[\mathrm{UO}_{2}\left(\mathrm{NO}_{3}\right)_{2}\left(\mathrm{H}_{2} \mathrm{O}\right)_{2}\right] \cdot 4 \mathrm{H}_{2} \mathrm{O}(35 \mathrm{mg}, 0.07 \mathrm{mmol})$, and $\left[\mathrm{Ni}(\right.$ cyclam $\left.)\left(\mathrm{NO}_{3}\right)_{2}\right](20 \mathrm{mg}, 0.05 \mathrm{mmol})$ were dissolved in water $(0.8 \mathrm{~mL})$ and DMF $(0.2 \mathrm{~mL})$. Orange-yellow crystals of complex 4 were obtained within four days (23 mg, 52\% yield based on U). Anal. Calcd for $\mathrm{C}_{28} \mathrm{H}_{40} \mathrm{~N}_{4} \mathrm{NiO}_{18} \mathrm{U}_{2}: \mathrm{C}, 26.79 ; \mathrm{H}, 3.21 ; \mathrm{N}, 4.46$. Found: C, 26.73; H, 2.95; N, 4.70\%.

$\left[\mathrm{UO}_{2}(\mathrm{adp})(\mathrm{HCOO})_{2} \mathrm{Cu}\left(\mathrm{R}, \mathrm{S}-\mathrm{Me}_{6} \mathrm{Cyclam}\right)\right] \cdot 2 \mathrm{H}_{2} \mathrm{O}$ (5) and $\left[\mathrm{H}_{2} \mathrm{NMe}_{2}\right]_{2}\left[\left(\mathrm{UO}_{2}\right)_{2}(\mathrm{adp})_{3}\right]$ (6). Adipic acid $(15 \mathrm{mg}, 0.10 \mathrm{mmol}),\left[\mathrm{UO}_{2}\left(\mathrm{NO}_{3}\right)_{2}\left(\mathrm{H}_{2} \mathrm{O}\right)_{2}\right] \cdot 4 \mathrm{H}_{2} \mathrm{O}(35 \mathrm{mg}, 0.07 \mathrm{mmol})$, and $[\mathrm{Cu}(R, S-$ $\mathrm{Me}_{6}$ cyclam $\left.)\left(\mathrm{NO}_{3}\right)_{2}\right](24 \mathrm{mg}, 0.05 \mathrm{mmol})$ were dissolved in water $(0.7 \mathrm{~mL})$ and DMF $(0.2 \mathrm{~mL})$. A mixture of light purple crystals of complex $\mathbf{5}$ and a smaller quantity of yellow crystals of complex 6 was obtained within two months. Crystals of the two species were selected for structure analysis, but no separation of the bulk was made.

$\left[\left(\mathrm{UO}_{2}\right)_{3}(\mathrm{muc})_{2}(\mathrm{O})_{2} \mathrm{Cu}\left(\mathrm{R}, \mathrm{S}-\mathrm{Me}_{6} \mathrm{Cyclam}\right)\right]$ (7). trans,trans-Muconic acid (14 mg, 0.10 mmol), $\left[\mathrm{UO}_{2}\left(\mathrm{NO}_{3}\right)_{2}\left(\mathrm{H}_{2} \mathrm{O}\right)_{2}\right] \cdot 4 \mathrm{H}_{2} \mathrm{O}(35 \mathrm{mg}, 0.07 \mathrm{mmol})$, and $\left[\mathrm{Cu}\left(R, S-\mathrm{Me}_{6} \mathrm{cyclam}\right)\left(\mathrm{NO}_{3}\right)_{2}\right](24$ $\mathrm{mg}, 0.05 \mathrm{mmol})$ were dissolved in water $(0.7 \mathrm{~mL})$ and DMF $(0.2 \mathrm{~mL})$. A few orange-pink crystals of complex 7 were obtained within one week.

$\left[\mathrm{PPh}_{3} \mathrm{Me}_{2}\left[\left(\mathrm{UO}_{2}\right)_{2}(\mathrm{adp})_{3}\right] \cdot 4 \mathrm{H}_{2} \mathrm{O} \quad\right.$ (8). Adipic acid (15 mg, 0.10 mmol), $\left[\mathrm{UO}_{2}\left(\mathrm{NO}_{3}\right)_{2}\left(\mathrm{H}_{2} \mathrm{O}\right)_{2}\right] \cdot 4 \mathrm{H}_{2} \mathrm{O}(35 \mathrm{mg}, 0.07 \mathrm{mmol})$, and $\mathrm{PPh}_{3} \mathrm{MeBr}(36 \mathrm{mg}, 0.10 \mathrm{mmol})$ were dissolved in water $(0.7 \mathrm{~mL})$ and DMF $(0.2 \mathrm{~mL})$. Yellow crystals of complex 8 were obtained within two months (41 mg, 73\% yield based on U). Anal. Calcd for $\mathrm{C}_{56} \mathrm{H}_{68} \mathrm{O}_{20} \mathrm{P}_{2} \mathrm{U}_{2}$ : C, 42.06; H, 4.29. Found: C, 41.63; H, 4.14\%. 
$\left[\mathrm{PPh}_{3} \mathrm{Me}_{2}\left[\left(\mathrm{UO}_{2}\right)_{2}(\mathrm{muc})_{3}\right] \cdot \mathrm{H}_{2} \mathrm{O}\right.$ (9). trans, trans-Muconic acid (14 mg, $\left.0.10 \mathrm{mmol}\right)$, $\left[\mathrm{UO}_{2}\left(\mathrm{NO}_{3}\right)_{2}\left(\mathrm{H}_{2} \mathrm{O}\right)_{2}\right] \cdot 4 \mathrm{H}_{2} \mathrm{O}(35 \mathrm{mg}, 0.07 \mathrm{mmol})$, and $\mathrm{PPh}_{3} \mathrm{MeBr}(36 \mathrm{mg}, 0.10 \mathrm{mmol})$ were dissolved in water $(0.7 \mathrm{~mL})$ and DMF $(0.2 \mathrm{~mL})$. Yellow crystals of complex 9 were obtained within two weeks (34 mg, 63\% yield based on $\mathrm{U}$ ). Anal. Calcd for $\mathrm{C}_{56} \mathrm{H}_{50} \mathrm{O}_{17} \mathrm{P}_{2} \mathrm{U}_{2}$ : C, 43.88; H, 3.29. Found: C, 44.12; H, 3.19\%.

Crystallography. The data for all compounds but 2 were collected at 100(2) K (293 K for 3) on a Bruker D8 Quest diffractometer equipped with an Incoatec microfocus source (I $\mu \mathrm{S} 3.0 \mathrm{Mo}, \lambda=0.71073 \AA$ ) and a PHOTON III area detector, and operated through the APEX3 software. ${ }^{37}$ Data for 2 were collected at 100(2) K on a Nonius Kappa-CCD area detector diffractometer ${ }^{38}$ using graphite-monochromated Mo K $\alpha$ radiation. The crystals were mounted into glass capillaries or on Mitegen micromounts with a protective coating of Paratone-N oil (Hampton Research). The data were processed with HKL2000 ${ }^{39}$ (2) or SAINT ${ }^{40}$ (all other compounds). Absorption effects were corrected empirically with the programs SCALEPACK (2) $^{39}$ or SADABS ${ }^{41,42}$ (all other compounds). All structures were solved by intrinsic phasing with SHELXT ${ }^{43}$ and refined by full-matrix least-squares on $F^{2}$ with SHELXL, ${ }^{44}$ using the ShelXle interface. ${ }^{45}$ All non-hydrogen atoms were refined with anisotropic displacement parameters. When present, the hydrogen atoms bound to oxygen and nitrogen atoms were retrieved from residual electron density maps when possible, and they were either refined or treated as riding atoms. The carbon-bound hydrogen atoms were introduced at calculated positions and were treated as riding atoms with an isotropic displacement parameter equal to 1.2 times that of the parent atom (1.5 for $\mathrm{CH}_{3}$, with optimized geometry). In complex $\mathbf{3}$, one adipate ligand is disordered over two positions related by inversion, so that one complete anion has been refined with half-occupancy. For compounds 6 and 7, some disordered water molecules could not be modelled satisfactorily and the SQUEEZE software ${ }^{46}$ was used to 
subtract their contribution to the structure factors. In compound 7, the $\mathrm{Cu}\left(R, S-\mathrm{Me}_{6}\right.$ cyclam $)$ moiety is badly resolved due to extended disorder, which proved impossible to model properly,

Table 1. Crystal Data and Structure Refinement Details

\begin{tabular}{|c|c|c|c|c|c|}
\hline & 1 & 2 & 3 & 4 & 5 \\
\hline chemical formula & $\mathrm{C}_{66} \mathrm{H}_{64} \mathrm{O}_{16} \mathrm{P}_{2} \mathrm{U}_{2}$ & $\mathrm{C}_{48} \mathrm{H}_{46} \mathrm{~N}_{6} \mathrm{NiO}_{21} \mathrm{U}_{2}$ & $\mathrm{C}_{28} \mathrm{H}_{52} \mathrm{~N}_{4} \mathrm{NiO}_{18} \mathrm{U}_{2}$ & & $\mathrm{C}_{24} \mathrm{H}_{50} \mathrm{CuN}_{4} \mathrm{O}_{12} \mathrm{U}$ \\
\hline$M\left(\mathrm{~g} \mathrm{~mol}^{-1}\right)$ & 1651.17 & 1577.68 & \multirow{2}{*}{$\begin{array}{l}1267.50 \\
\text { monoclinic }\end{array}$} & $\begin{array}{l}\mathrm{C}_{28} \mathrm{H}_{40} \mathrm{~N}_{4} \mathrm{~N}_{1} \mathrm{O}_{18} \mathrm{U}_{2} \\
1255.41\end{array}$ & 888.25 \\
\hline cryst syst & triclinic & triclinic & & monoclinic & triclinic \\
\hline space group & $P \overline{1}$ & $P \overline{1}$ & $P 2_{1} / n$ & $P 21 / n$ & $P \overline{1}$ \\
\hline$a(\AA)$ & $9.2276(5)$ & $13.1434(6)$ & $9.6144(3)$ & & $9.0967(3)$ \\
\hline$b(\AA)$ & $13.4451(7)$ & $13.2308(6)$ & $16.2293(4)$ & $\begin{array}{l}10.3105(5) \\
16.3220(8)\end{array}$ & $9.3102(3)$ \\
\hline$c(\AA)$ & $13.5850(7)$ & $15.5878(4)$ & $13.3108(4)$ & $11.8107(6)$ & $10.5452(4)$ \\
\hline$\alpha(\operatorname{deg})$ & $72.277(3)$ & $82.524(3)$ & 90 & 90 & $108.9845(13)$ \\
\hline$\beta(\operatorname{deg})$ & $89.303(3)$ & $87.781(3)$ & $105.9155(12)$ & $101.981(2)$ & $105.8564(15)$ \\
\hline$\gamma(\mathrm{deg})$ & $73.470(2)$ & $85.852(2)$ & 90 & 90 & $99.6708(15)$ \\
\hline$V\left(\AA^{3}\right)$ & $1533.97(14)$ & $2679.42(19)$ & 1997.34(10) & $1944.30(17)$ & $779.32(5)$ \\
\hline$Z$ & 1 & 2 & 2 & 2 & 1 \\
\hline reflns collcd & 19495 & 149099 & 130461 & 146251 & 13815 \\
\hline indep reflns & 5748 & 10134 & 3757 & 5936 & 2953 \\
\hline obsd reflns $[I>2 \sigma(I)]$ & 4980 & 8703 & 3599 & 5503 & 2933 \\
\hline$R_{\text {int }}$ & 0.046 & 0.031 & 0.048 & 0.073 & 0.050 \\
\hline params refined & 388 & 703 & 302 & 255 & 208 \\
\hline$R_{1}$ & 0.047 & 0.026 & 0.027 & 0.020 & 0.025 \\
\hline$w R_{2}$ & 0.109 & 0.065 & 0.066 & 0.045 & 0.066 \\
\hline$S$ & 1.108 & 1.030 & 1.116 & 1.105 & 1.050 \\
\hline$\Delta \rho_{\min }\left(\mathrm{e} \AA^{-3}\right)$ & -1.58 & -1.22 & -1.27 & -0.93 & -0.94 \\
\hline$\Delta \rho_{\max }\left(\mathrm{e} \AA^{-3}\right)$ & 3.09 & 1.61 & 2.26 & 1.71 & 3.40 \\
\hline & 6 & 7 & & 8 & 9 \\
\hline chemical formula & $\mathrm{C}_{22} \mathrm{H}_{40} \mathrm{~N}_{2} \mathrm{O}_{16} \mathrm{U}_{2}$ & $\mathrm{C}_{28} \mathrm{H}_{44} \mathrm{CuN}_{4} \mathrm{C}$ & $\mathrm{C}_{56} \mathrm{H}_{68} \mathrm{O}$ & ${ }_{20} \mathrm{P}_{2} \mathrm{U}_{2}$ & $\mathrm{H}_{50} \mathrm{O}_{17} \mathrm{P}_{2} \mathrm{U}_{2}$ \\
\hline$M\left(\mathrm{~g} \mathrm{~mol}^{-1}\right)$ & 1064.62 & 1470.30 & 1599.10 & & 2.96 \\
\hline cryst syst & monoclinic & triclinic & monocli & nic & norhombic \\
\hline space group & $P 2_{1} / n$ & $P \overline{1}$ & $P 2_{1} / c$ & $\mathrm{~Pb}$ & \\
\hline$a(\AA)$ & $14.8024(5)$ & $11.6426(5)$ & 17.8878 & & $6626(3)$ \\
\hline$b(\AA)$ & $9.4939(3)$ & $14.1014(7)$ & 16.0115 & (6) & $8415(5)$ \\
\hline$c(\AA)$ & $24.6640(8)$ & $14.8977(6)$ & 22.6503 & (9) & 7926(9) \\
\hline$\alpha(\mathrm{deg})$ & 90 & $97.6144(19)$ & 90 & 90 & \\
\hline$\beta(\operatorname{deg})$ & $106.1389(16)$ & $106.7181(18)$ & 112.977 & $6(17)$ & \\
\hline$\gamma(\operatorname{deg})$ & 90 & $90.480(2)$ & 90 & 90 & \\
\hline$V\left(\AA^{3}\right)$ & $3329.50(19)$ & $2319.04(18)$ & 5972.6( & & $29.6(3)$ \\
\hline$Z$ & 4 & 2 & 4 & 4 & \\
\hline reflns colled & 130706 & 162948 & 11329 & & 149 \\
\hline indep reflns & 8578 & 8777 & 11329 & 71 & \\
\hline obsd reflns $[I>2 \sigma(I)]$ & 8048 & 8394 & 10391 & 62 & \\
\hline$R_{\text {int }}$ & 0.063 & 0.054 & 0.066 & 0. & \\
\hline params refined & 400 & 472 & 808 & 35 & \\
\hline$R_{1}$ & 0.026 & 0.033 & 0.039 & & \\
\hline$w R_{2}$ & 0.061 & 0.085 & 0.088 & & \\
\hline$S$ & 1.166 & 1.052 & 1.131 & & \\
\hline$\Delta \rho_{\min }\left(\mathrm{e} \AA^{-3}\right)$ & -1.32 & -1.97 & -1.52 & & \\
\hline$\Delta \rho_{\max }\left(\mathrm{e} \AA^{-3}\right)$ & 2.66 & 2.42 & 1.91 & 1. & \\
\hline
\end{tabular}


and the average position of the macrocycle only was refined with restraints on bond lengths and displacement parameters, the hydrogen atoms bound to nitrogen atoms being introduced at calculated positions. In compound $\mathbf{8}$, which is a two-component twin, one adipate carbon chain is partly disordered over two positions related by symmetry, and one aromatic ring is rotationally disordered over two positions. Crystal data and structure refinement parameters are given in Table 1. The molecular plots were drawn with ORTEP-3, ${ }^{47}$ and the polyhedral representations with VESTA. ${ }^{48}$ The topological analyses and nodal representations were made with ToposPro. ${ }^{49}$

\section{RESULTS AND DISCUSSION}

Crystals of complexes 1-9 were grown under solvo-hydrothermal conditions, at a temperature of $140{ }^{\circ} \mathrm{C}$. The organic cosolvent was DMF in all cases but that of complex $\mathbf{1}$, for which it was NMP. These syntheses provide yet further examples of the difficulty of predicting the nature of the products obtained under solvo-hydrothermal conditions and indicate the complicated nature of the solutions, where numerous components must be in equilibrium, from which crystals may deposit. DMF, a very useful solvent for the initial formation of a homogeneous solution of organic and inorganic reagents in the present instances, nonetheless has the disadvantage of undergoing hydrolysis, probably metal ion-catalyzed, to generate formate and dimethylammonium ions, one or both of which can appear in the isolated products, and found here in complexes $\mathbf{5}$ and $\mathbf{6}$, obtained together in the same experiment, respectively. Hence, in the continued absence of a detailed knowledge of the solution equilibria occurring in solvothermal media, progress in solvothermal synthesis remains an empirical process.

After $\left[\mathrm{PPh}_{4}\right]\left[\mathrm{UO}_{2}(\operatorname{adp})\left(\mathrm{NO}_{3}\right)\right],{ }^{27}$ in which the terminal nitrate ligand limits the polymer formed to being monoperiodic, $\left[\mathrm{PPh}_{4}\right]_{2}\left[\left(\mathrm{UO}_{2}\right)_{2}(\operatorname{adp})_{3}\right](\mathbf{1})$ is the second uranyl adipate complex incorporating $\mathrm{PPh}_{4}{ }^{+}$cations. The only difference between the syntheses of these two complexes 
is the presence of NMP as a cosolvent in the case of $\mathbf{1}$, while the previous complex was obtained under purely hydrothermal conditions, a further proof of the frequently subtle and unpredictable role of cosolvents. The asymmetric unit in complex 1 contains one uranyl cation and three centrosymmetric adp ${ }^{2-}$ ligands (Figure 1). The metal cation is tris- $\kappa^{2} O, O^{\prime}$-chelated by three

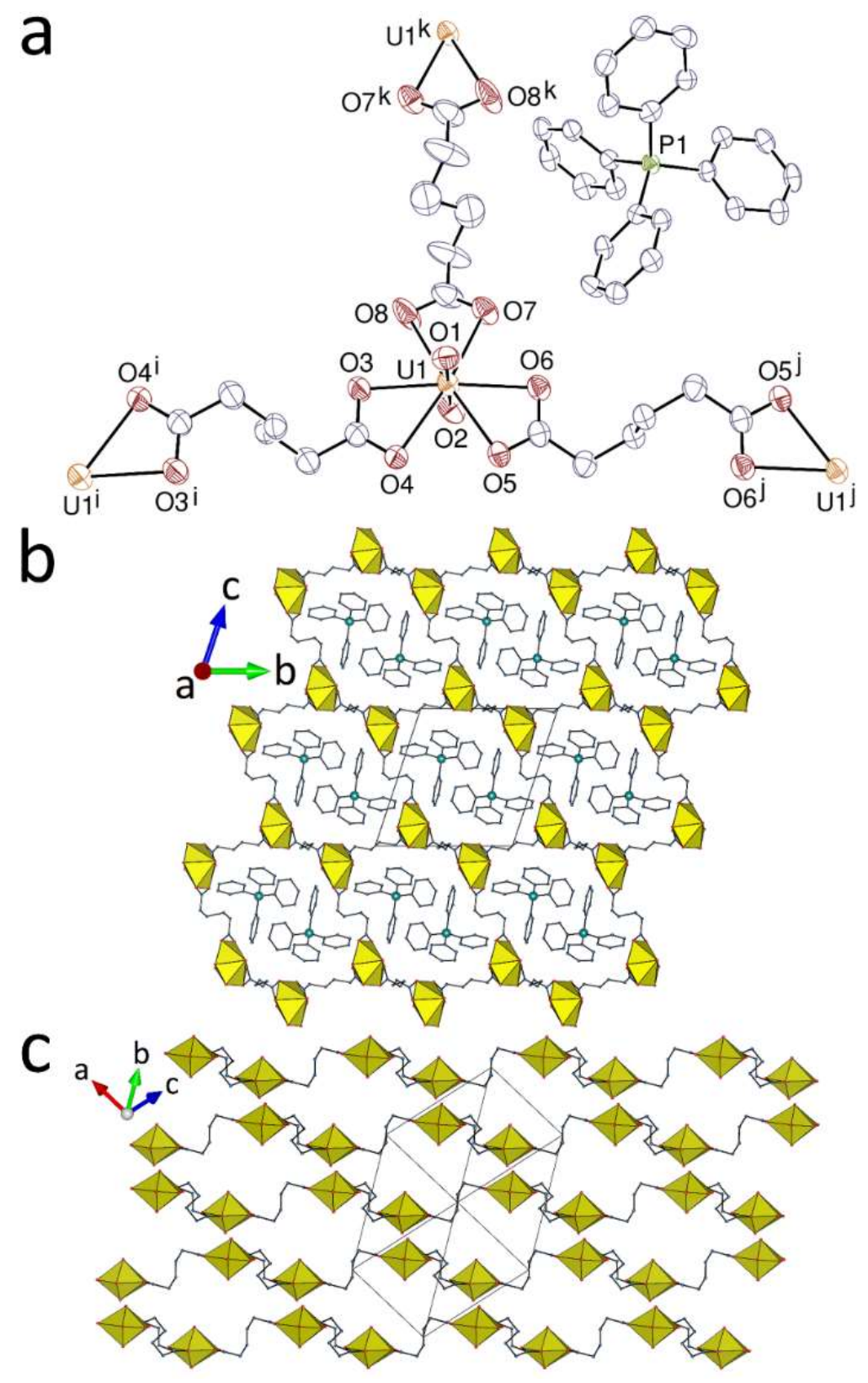

Figure 1. (a) View of compound 1. Displacement ellipsoids are drawn at the 50\% probability level and hydrogen atoms are omitted. Symmetry codes: $\mathrm{i}=-x, 2-y, 2-z ; \mathrm{j}=2-x, 1-y, 2-z ; \mathrm{k}=1-x, 2-y, 1-z$. (b) View of the diperiodic polymer with uranium coordination polyhedra colored yellow. (c) Packing with sheets viewed edgeon and counterions omitted for clarity. 
carboxylate groups, as commonly found in uranyl carboxylate complexes [U-O(oxo), 1.781(6) and 1.787(6) $\AA, \mathrm{U}-\mathrm{O}($ carboxylato), 2.409(6)-2.473(6) $\AA]$. None of the three ligands adopts the fully extended conformation, all being kinked and S-shaped. The diperiodic coordination polymer formed, parallel to (121), has the vertex symbol $\left\{6^{3}\right\}$ and the hcb topological type. When viewed edge-on, the layers are heavily puckered, with the uranium atoms appearing to lie in two parallel planes, and they are packed in bump-to-bump fashion, so that narrow channels are defined. Each ring encircles two $\mathrm{PPh}_{4}{ }^{+}$cations but with no parallel $\pi$-stacking interaction revealed by short contact analysis with PLATON,${ }^{50}$ all centroid $\cdots$ centroid distances being larger than $4.7 \AA$. The P...P separation of 8.507(4) $\AA$ for these two cations is long for any "embrace" interaction ${ }^{51}$ and in fact the two are linked by $\mathrm{CH} \cdots \mathrm{O}$ interactions ${ }^{52,53}$ with two uranyl oxo groups. The shortest P...P separation of 6.638(4) $\AA$ involves cations in adjacent sheets with interactions beyond dispersion in the form of reciprocal $\mathrm{CH} \cdots \pi$ interactions ( $\mathrm{H} \cdots$ centroid distance, $2.87 \AA ; \mathrm{C}-\mathrm{H} \cdots$ centroid angle, $132^{\circ}$ ). It is thus possible to find from the observed interactions beyond dispersion a unit based on the closest pair of phosphonium cations which would lead to a diperiodic polymer. The Kitaigorodski packing index (KPI, calculated with PLATON) is 0.69 , indicating no significant porosity.

Complex 2, [Ni(bipy) $\left.)_{3}\right]\left[\left(\mathrm{UO}_{2}\right)_{2}(\text { muc })_{3}\right] \cdot 5 \mathrm{H}_{2} \mathrm{O}$, shown in Figure 2, also displays tris$\kappa^{2} O, O^{\prime}$-chelation of the two independent uranium atoms [U-O(oxo), 1.755(3)-1.775(3) $\AA$, U-

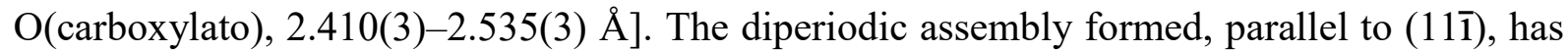
also the hcb topology, but the rigid, elongated form of the ligand makes it much more regular and closer to planarity than that in complex $\mathbf{1}$. The hexanuclear rings are slightly elongated, with largest and smallest dimensions of 23 and $17 \AA$. The geometry of the network is much 


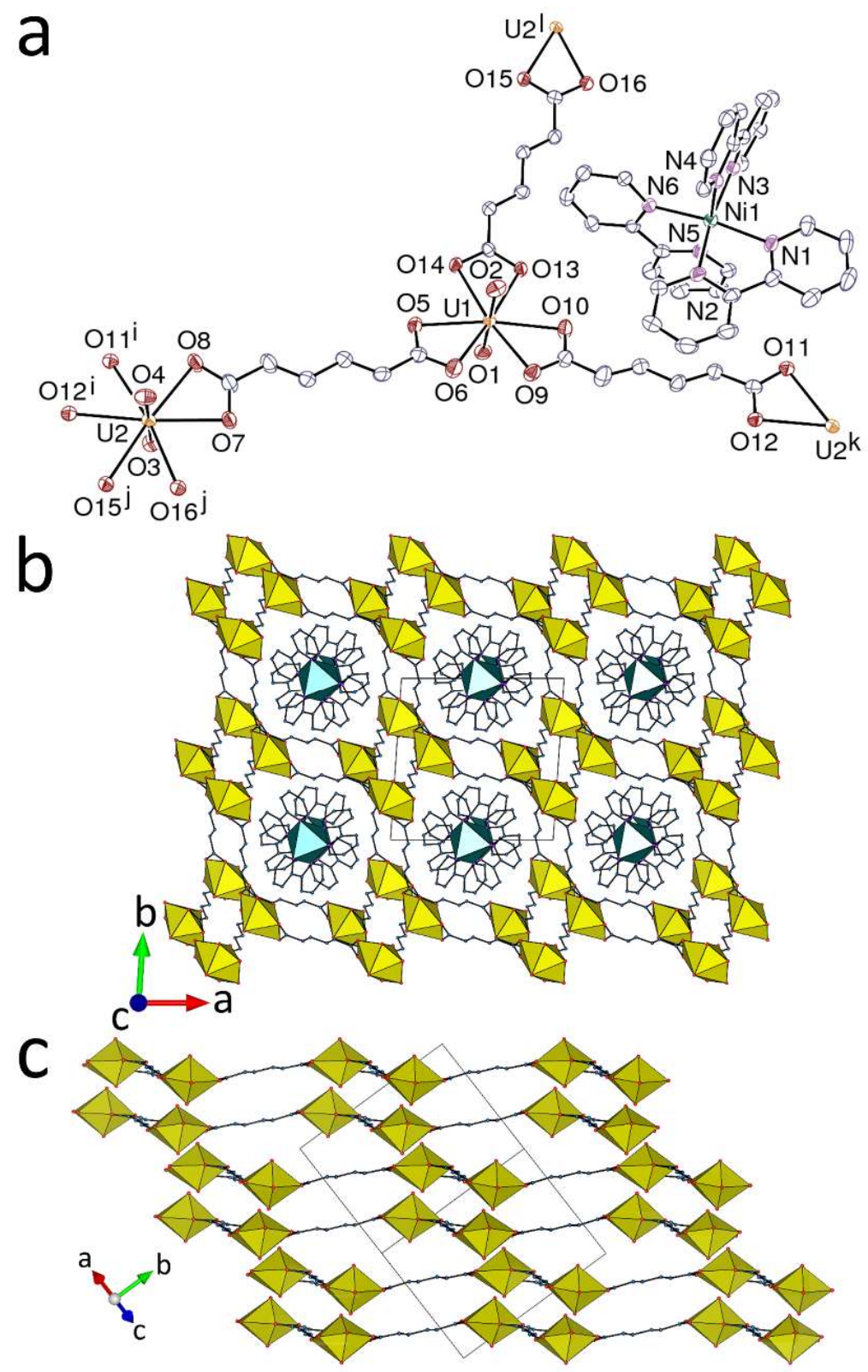

Figure 2. (a) View of compound 2. Displacement ellipsoids are drawn at the $50 \%$ probability level. Solvent molecules and hydrogen atoms are omitted. Symmetry codes: $\mathrm{i}=x, y-1, z-1 ; \mathrm{j}=x-1, y, z-1 ; \mathrm{k}=x, y+1, z+$ $1 ; 1=x+1, y, z+1$. (b) and (c) Packing with sheets viewed obliquely or edge-on, respectively; counterions are omitted in (c) for clarity.

simpler than that of the complexes including the same counterion and the saturated aliphatic dicarboxylates with $n=10$ and $12 .{ }^{54}$ The octahedral $\left[\mathrm{Ni}(\text { bipy })_{3}\right]^{2+}$ counterions occupy the channels that run parallel to [001], with the chirality alternating along the column and the cations involved in an "embrace" interaction involving reciprocal $\mathrm{CH} \cdots \pi$ interactions exceeding 
dispersion, as shown by the Hirshfeld surface (HS) ${ }^{55}$ calculated with CrystalExplorer (ver. 3.1). ${ }^{56}$ The columns of cations may be seen as associated with the diperiodic nets in polythreading-like way, leading to a compact packing (KPI, 0.68). Each cation is encircled by a 54-membered ring of a polymer sheet but lies off-centre, so that it is closest to a unit involving the two inequivalent uranium centres and the three inequivalent ligands. As usual, $\mathrm{CH} \cdots \mathrm{O}$ hydrogen bonds involving the cations are numerous and it appears that they could promote the formation of a sheet structure without any entanglement through association with the columns of interacting cations. Crystals of $\left[\mathrm{H}_{2} \mathrm{NMe}_{2}\right]_{2}\left[\left(\mathrm{UO}_{2}\right)_{2}(\mathrm{muc})_{3}\right] \cdot x \mathrm{H}_{2} \mathrm{O}$ were also obtained together with those of 2; this complex displays also an hcb network with no entanglement, but the crystal quality was insufficient for proper structure refinement.

Heterometallic complexes including $\mathrm{Ni}(\text { cyclam })^{2+}$ moieties were obtained with both $\operatorname{adp}^{2-}$ and $\mathrm{muc}^{2-}$, and they appear to have very different crystal structures. The asymmetric unit in $\left[\left(\mathrm{UO}_{2}\right)_{2}(\operatorname{adp})_{3} \mathrm{Ni}(\right.$ cyclam $\left.)\right] \cdot 2 \mathrm{H}_{2} \mathrm{O}(3)$ contains one uranium cation which is $\kappa^{2} O, O^{\prime}$-chelated by one carboxylate group and bound to three more carboxylate oxygen atoms from three additional ligands, and is thus in a pentagonal-bipyramidal environment [U-O(oxo), 1.762(4) and 1.770(4) $\AA$; U-O(carboxylato), 2.472(4) and 2.478(4) $\AA$ for the chelating group, and 2.31(2)-2.35(3) A for the others] (Figure 3). The presence of axial sites suited only to relatively weak coordination of a single donor atom (even when assisted by NH-hydrogen bonding) renders $[\mathrm{Ni}(\text { cyclam })]^{2+}$ a poor competitor with uranyl ion for carboxylate binding but it nonetheless is able to perturb significantly the $\left[\left(\mathrm{UO}_{2}\right)_{2}(\mathrm{adp})_{3}\right]^{2-}$ unit which, containing uranyl and carboxylate groups in the ratio $1: 3$, might have been expected ${ }^{26}$ to adopt a diperiodic polymer form with $\mathrm{U}^{\mathrm{VI}}$ in hexagonal-bipyramidal coordination. Here, with relatively short $\mathrm{Ni}-$ O bonds [2.154(3) $\AA$, compared to Ni-N, 2.055(4) and 2.060(4) $\AA]$ assisted by hydrogen bonding $\left[\mathrm{N} 1 \cdots \mathrm{O} 3,2.946(6) \AA ; \mathrm{N} 1-\mathrm{H} \cdots \mathrm{O} 3,152(6)^{\circ}\right], \mathrm{Ni}^{\mathrm{II}}$ is apparently able to enforce $\mu_{2-}$ $\kappa^{1} O: \kappa^{1} O^{\prime}$-bridging between $\mathrm{Ni}^{\mathrm{II}}$ and $\mathrm{U}^{\mathrm{VI}}$ and prevent $\kappa^{2} O, O^{\prime}$-chelation to $\mathrm{U}^{\mathrm{VI}}$ by the carboxylate 


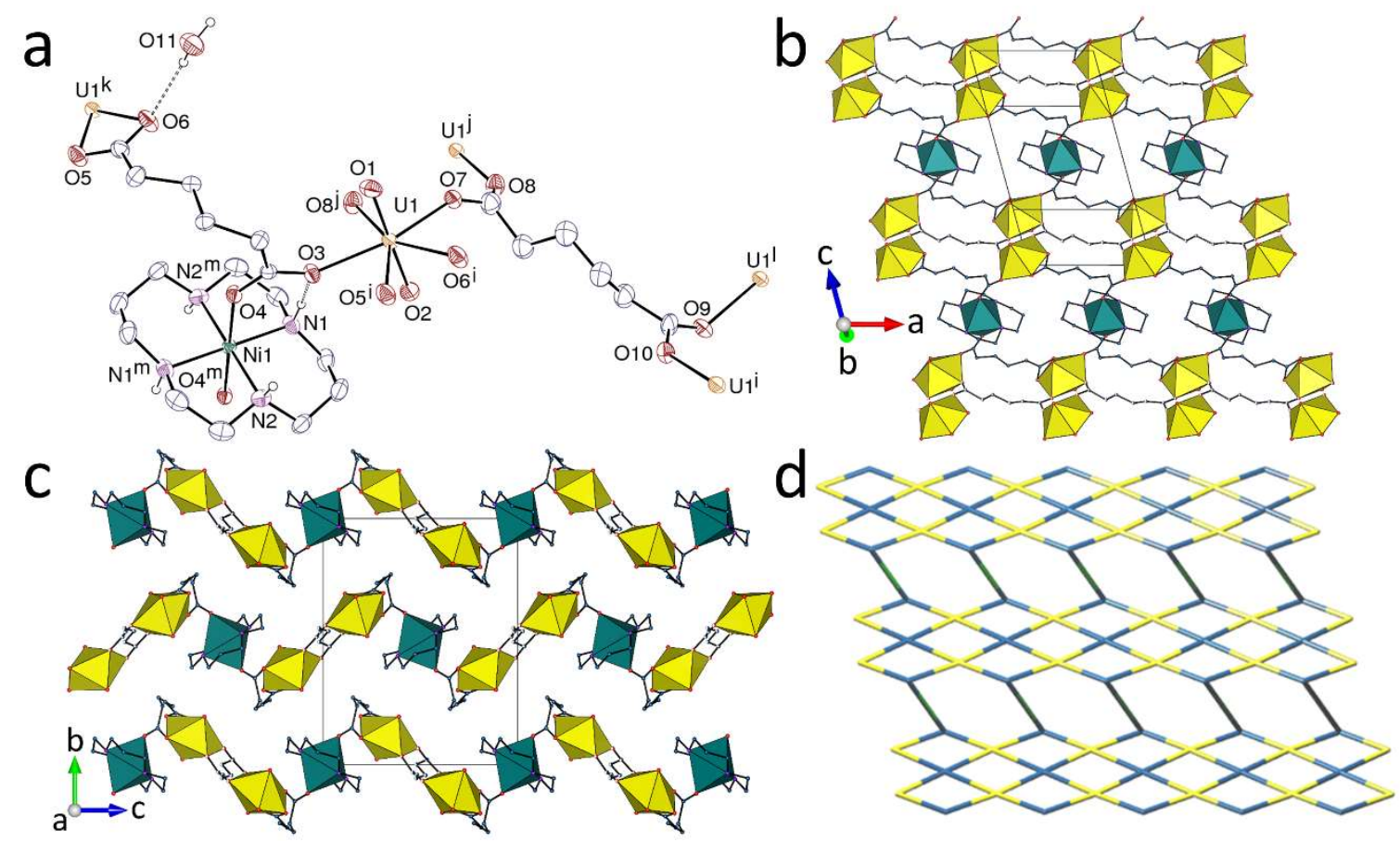

Figure 3. (a) View of compound 3. Displacement ellipsoids are drawn at the $30 \%$ probability level. Carbon-bound hydrogen atoms are omitted and hydrogen bonds are shown as dashed lines. Only one position of the disordered dicarboxylate ligand is shown. Symmetry codes: $\mathrm{i}=x+1, y, z ; \mathrm{j}=2-x, 1-y, 2-z ; \mathrm{k}=x-1, y, z ; 1=3-x, 1-$ $y, 2-z ; \mathrm{m}=1-x, 1-y, 1-z$. (b) View of the diperiodic coordination polymer with uranium coordination polyhedra yellow and those of nickel green. (c) Packing with sheets viewed edge-on. (d) Nodal representation of the network (uranium nodes, yellow; nickel links, green; dicarboxylate nodes, dark blue; same orientation as in part b).

unit involved. Such $\mu_{2}-\kappa^{1} O: \kappa^{1} O^{\prime}$-bridging of another adipate also links the uranium atoms into centrosymmetric units. One adp ${ }^{2-}$ ligand has one carboxylate group chelating and the other bridging uranium and nickel atoms in syn/anti $\mu_{2}-\kappa^{1} O: \kappa^{1} O^{\prime}$ mode, while the other, which is disordered around an inversion centre (see Experimental Section), links four uranium atoms in the $\operatorname{bis}\left(\mu_{2}-\kappa^{1} O: \kappa^{1} O^{\prime}\right)$ mode. Uranium is thus a 4-coordinated (4-c) node, the adp ${ }^{2-}$ ligands are 3-c and 4-c nodes and nickel is a simple link in the diperiodic, 3-nodal network formed, parallel to (010), which has the vertex symbol $\left\{4 \cdot 6^{2}\right\}_{2}\left\{4^{3} \cdot 6^{3}\right\}_{2}\left\{4^{4} \cdot 6^{2}\right\}$. The same topology, involving monoperiodic uranyl-dicarboxylate subunits, running here along [100], linked to one another 
by the nickel centres, has previously been found in a complex with 1,3-phenylenediacetate, also containing Ni(cyclam) $)^{2+}$ cations. $^{57}$ This topology is akin to the more common 3,4L13, found for example in the complex with 1,3-adamantanediacetate including $\mathrm{Ni}\left(R, S \text {-Me }{ }_{6} \text { cyclam }\right)^{2+}$ cations, ${ }^{58}$ with the simple monoperiodic subunits in the latter replaced here by larger, triplystranded ribbons. These ribbons are close to planar, bridging of these units by $\mathrm{Ni}^{\mathrm{II}}$ resulting in corrugated sheets with a sawtooth profile when viewed down [100]. The fact that no entanglement is observed here, as well as in subsequent cases where azamacrocyclic complexes are involved, arises primarily from the insufficient available space in the rings, the shortest distance between carbon atoms in proximal macrocycles being 3.679(14) $\AA$, but it may also be noted that a species such as $\left[\mathrm{Ni}(\mathrm{cyclam})(\operatorname{adp})_{2}\right]^{2-}$ has no obvious features to explain possible self-association and thus to begin polymerization involving separate strands which might ultimately become entangled.

The counterpart of 3 with the muc ${ }^{2-}$ ligand, $\left[\left(\mathrm{UO}_{2}\right)_{2}(\text { muc })_{3} \mathrm{Ni}(\right.$ cyclam $\left.)\right] \cdot 2 \mathrm{H}_{2} \mathrm{O}(\mathbf{4})$, has exactly the same stoichiometry and solvation, and the local environment of the cations is the same (Figure 4). The unique uranium atom is in a pentagonal-bipyramidal environment, with one chelating and three singly-bonded carboxylate groups [U-O(oxo), 1.7739(18) and

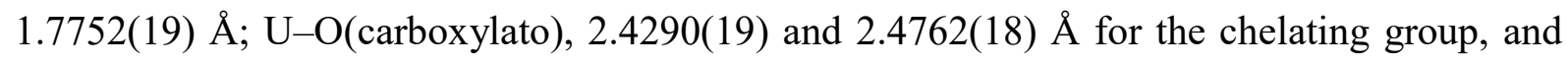
2.3221(17)-2.3515(18) $\AA$ for the others], and the nickel atom, located on an inversion centre (as in 3), is involved in two axial bonds with carboxylate donors, with a bond length even shorter than that in $3[\mathrm{Ni}-\mathrm{O}, 2.1197(17) \AA$; Ni-N, 2.063(2) and 2.071(2) $\AA]$. The usual hydrogen bond between the macrocycle and the carboxylate group bound to $\mathrm{Ni}^{\mathrm{II}}$ is present $\left[\mathrm{N} 1 \cdots \mathrm{O} 3,3.055(3) \AA ; \mathrm{N} 1-\mathrm{H} \cdots \mathrm{O} 3,151(3)^{\circ}\right]$. However, the different orientation of the carboxylate groups, due in part to the rigidity and planarity of the muc ${ }^{2-}$ ligand, results in the 


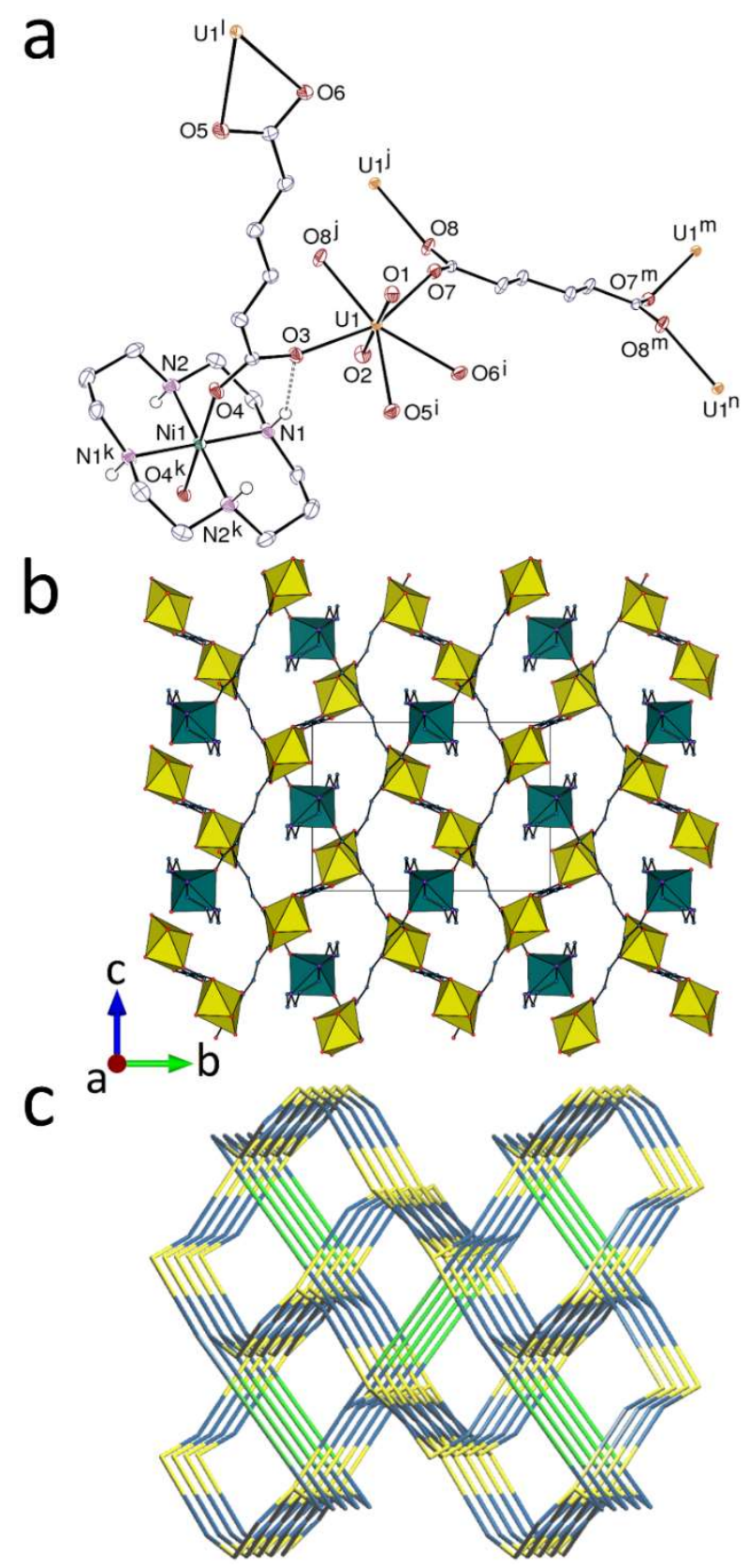

Figure 4. (a) View of compound 4. Displacement ellipsoids are drawn at the 50\% probability level. Solvent molecules and carbon-bound hydrogen atoms are omitted, and the hydrogen bond is shown as a dashed line. Symmetry codes: $\mathrm{i}=x-1 / 2,1 / 2-y, z+1 / 2 ; \mathrm{j}=1-x, 1-y, 1-z ; \mathrm{k}=2-x, 1-y, 2-z ; 1=x+1 / 2,1 / 2-y, z-$ $1 / 2 ; \mathrm{m}=-x, 1-y, 1-z ; \mathrm{n}=x-1, y, z$. (b) View of the triperiodic framework with uranium coordination polyhedra yellow and those of nickel green. (c) Nodal representation of the framework (uranium nodes, yellow; nickel links, green; dicarboxylate nodes, dark blue; orientation slightly rotated with respect to that in part b).

formation of a triperiodic, 3-nodal, 3,4,4-c network with the point symbol $\left\{4.8^{4} \cdot 10\right\}_{2}\left\{4^{2} \cdot 8^{2} \cdot 10^{2}\right\}\left\{8 \cdot 10^{2}\right\}_{2}$. Uranyl and muc ${ }^{2-}$ ligands alone form also a triperiodic 
assembly, which is 2-nodal $(4,4-c)$ and has the point symbol $\left\{4.6^{4} .8\right\}_{2}\left\{4^{2} \cdot 6^{2} \cdot 8^{2}\right\}$ and the mog (moganite) topological type ${ }^{59}$ this framework displays channels with an oblong section, within which the Ni centres stand as pillars. The triperiodic assembly does not display significant porosity, and the KPI is 0.67 .

The two complexes $\left[\mathrm{UO}_{2}(\operatorname{adp})(\mathrm{HCOO})_{2} \mathrm{Cu}\left(R, S-\mathrm{Me}_{6}\right.\right.$ cyclam $\left.)\right] \cdot 2 \mathrm{H}_{2} \mathrm{O} \quad$ (5) and $\left[\mathrm{H}_{2} \mathrm{NMe}_{2}\right]_{2}\left[\left(\mathrm{UO}_{2}\right)_{2}(\mathrm{adp})_{3}\right]$ (6) were crystallized from the same solution, and each of them incorporates one species formed from DMF hydrolysis, the formate coligand in $\mathbf{5}$ and the dimethylammonium counterion in $\mathbf{6}$. As shown in Figure 5, the unique uranium atom in 5,

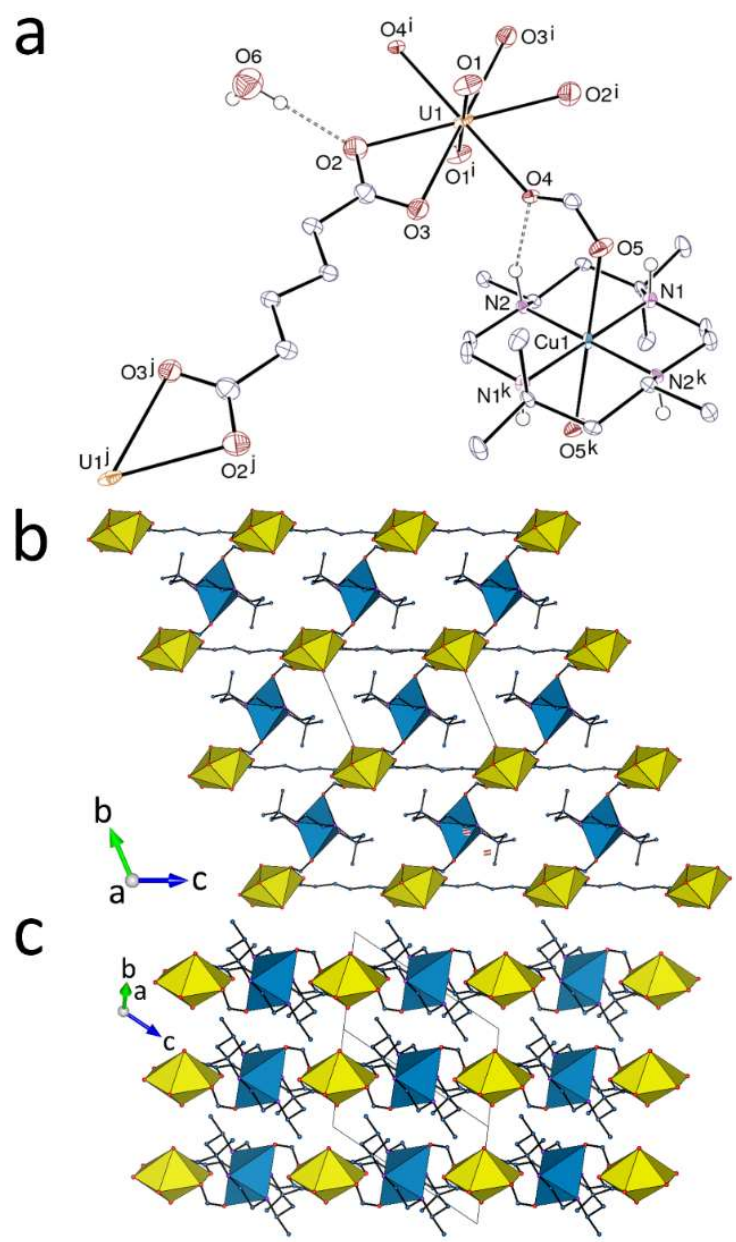

Figure 5. (a) View of compound 5. Displacement ellipsoids are drawn at the 50\% probability level. Carbon-bound hydrogen atoms are omitted and hydrogen bonds are shown as dashed lines. Symmetry codes: $\mathrm{i}=1-x,-y,-z ; \mathrm{j}=$ $2-x,-y, 1-z ; \mathrm{k}=1-x, 1-y, 1-z$. (b) View of the diperiodic coordination polymer with uranium coordination polyhedra yellow and those of copper blue. (c) Packing with sheets viewed edge-on. 
located on an inversion centre, is chelated by two carboxylate groups from two adp ${ }^{2-}$ ligands and is bound to two more carboxylate oxygen atoms from two formate anions which are bridging uranium and copper centres in the syn/anti $\mu_{2}-\kappa^{1} O: \kappa^{1} O^{\prime}$ mode, and it is thus in an hexagonal-bipyramidal environment [U-O(oxo), 1.768(3) A; U-O(carboxylato), 2.530(3) and 2.548(3) $\AA$ for the chelating group, and 2.378(3) $\AA$ for the formate ligand]. The $\operatorname{bis}\left(\kappa^{2} O, O^{\prime}\right)$ chelated form of the adp ${ }^{2-}$ ligand and its regular, extended conformation result in the formation of single-stranded, linear chains directed along [101], very similar to those seen in the structure of the simpler $\left[\mathrm{UO}_{2}(\operatorname{adp})\left(\mathrm{H}_{2} \mathrm{O}\right)_{2}\right]$ complex. ${ }^{24}$ Axial coordination of the syn/anti $\mu_{2}-\kappa^{1} O: \kappa^{1} O^{\prime}-$ bridging formate to $\mathrm{Cu}^{\mathrm{II}}$, also located on an inversion centre $[\mathrm{Cu}-\mathrm{O}, 2.524(3) \AA$; $\mathrm{Cu}-\mathrm{N}$, 2.017(3) and 2.061(3) $\AA$ ] results in the linkage of these chains into a uninodal, 4-c diperiodic network parallel to (11) $)$, which has the point symbol $\left\{4^{4} \cdot 6^{2}\right\}$ and the sql topological type. As

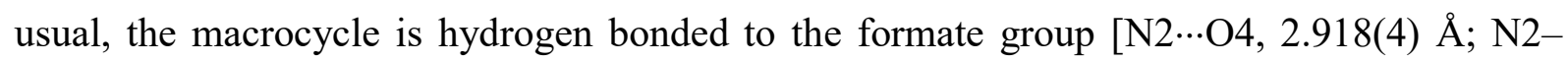
$\left.\mathrm{H} \cdots \mathrm{O} 4,155(4)^{\circ}\right]$, while the solvent water molecule is a hydrogen bond donor towards atom $\mathrm{O} 2$ and its symmetry equivalent in a neighbouring sheet $[\mathrm{O} \cdots \mathrm{O}, 2.876(6)$ and $3.128(6) \AA ; \mathrm{O}-\mathrm{H} \cdots \mathrm{O}$, 174(7) and $\left.174(6)^{\circ}\right]$, thus generating a weakly bonded triperiodic network (KPI, 0.72). As for complexes 3 and $\mathbf{4}$, the species $\mathrm{Cu}\left(R, S-\mathrm{Me}_{6}\right.$ cyclam $)(\mathrm{HCOO})_{2}$ is one where uranyl ion binding to the pendant formate carboxylates would place them well apart and one for which any selfassociation to initiate possible interpenetration would seem unlikely.

The asymmetric unit in complex $\mathbf{6},\left[\mathrm{H}_{2} \mathrm{NMe}_{2}\right]_{2}\left[\left(\mathrm{UO}_{2}\right)_{2}(\mathrm{adp})_{3}\right]$, contains two uranium centres, both of them tris $\left(\kappa^{2} O, O^{\prime}\right)$-chelated by three carboxylate groups and hence in a hexagonal-bipyramidal environment [U-O(oxo), 1.768(3)-1.780(3) Å; U-O(carboxylato), 2.444(3)-2.515(3) $\AA$, and the four inequivalent adp ${ }^{2-}$ ligands, two of them centrosymmetric, are bis-chelating (Figure 6). As in complexes $\mathbf{1}$ and $\mathbf{2}$, this bonding mode yields a diperiodic 


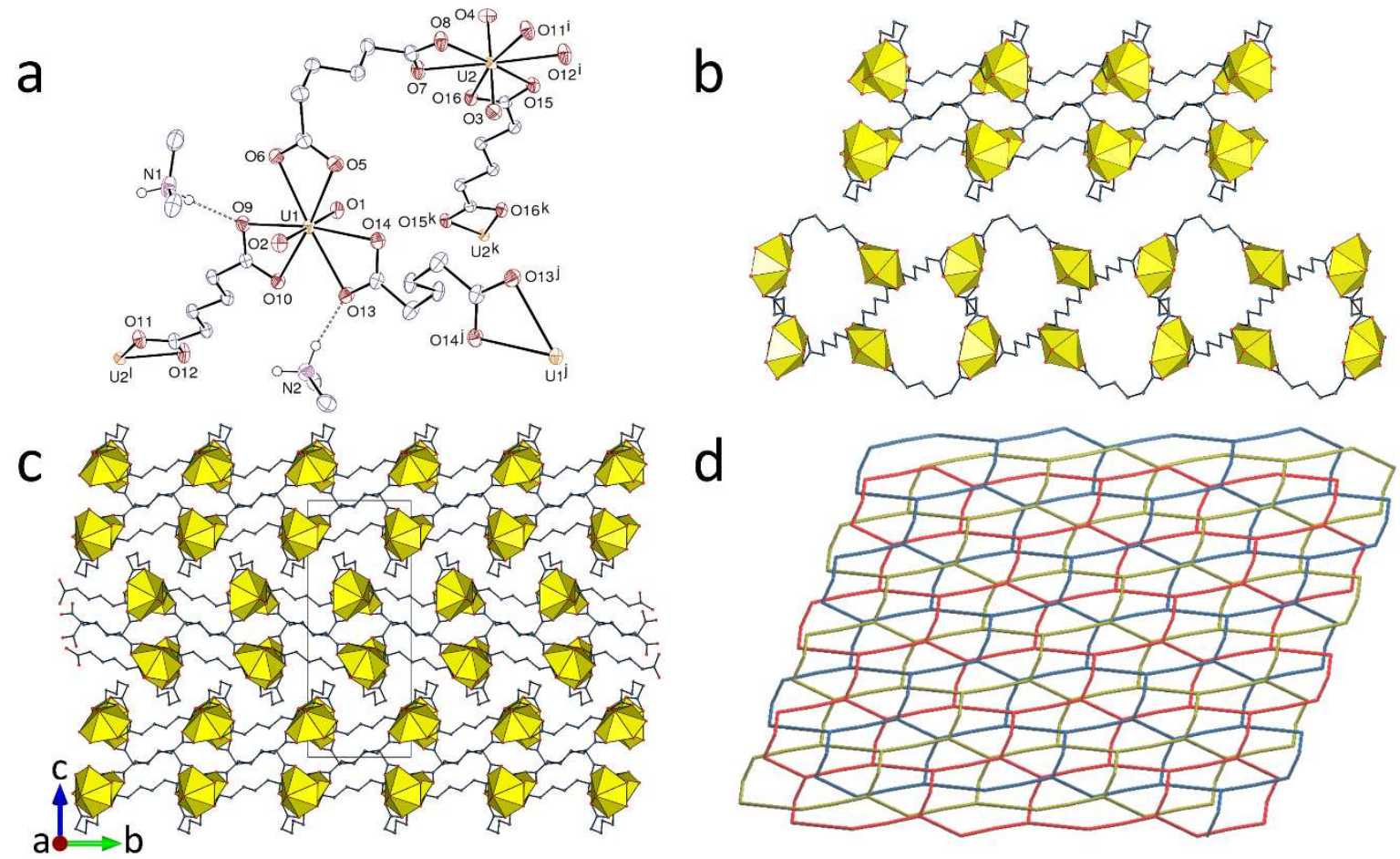

Figure 6. (a) View of compound 6. Displacement ellipsoids are drawn at the 50\% probability level. Carbon-bound hydrogen atoms are omitted and hydrogen bonds are shown as dashed lines. Symmetry codes: $\mathrm{i}=x+1, y-1, z ; \mathrm{j}$ $=1-x,-y, 1-z ; \mathrm{k}=2-x, 2-y, 1-z ; 1=x-1, y+1, z$. (b) Two views of the threefold interpenetrated diperiodic networks down [100] (top) or [010] (bottom). (c) Packing with sheets viewed edge-on and counterions omitted. (d) Simplified view of the threefold interpenetration of diperiodic networks down [001].

network of hcb topology parallel to (001), which has a distinctly ruffled shape with a squarewave profile arising from two of the ligands having kinked or curved conformations, the other two being regularly extended. This shape allows for threefold parallel interpenetration to occur, giving intricate sheets with a maximum thickness of $\sim 15 \AA$, which are stacked so as to bring the bumps corresponding to the protruding curved ligands of one sheet into the hollows defined by the extended ligands of the two neighbouring sheets. Threefold interpenetration of hcb networks has recently been reported to occur in a uranyl ion complex with 2,5thiophenedicarboxylate, ${ }^{35}$ in a case in which the undulations of the individual sheets were sufficiently important. The flexibility of the adp ${ }^{2-}$ ligand in $\mathbf{6}$ appears to play an essential role in endowing the network with sufficient corrugation. One of the $\mathrm{H}_{2} \mathrm{NMe}_{2}{ }^{+}$counterions 
(containing N1) and its symmetry equivalents are located near the boundary between two sheets, while the others (containing N2) are seated within the sheets and occupy tubular channels parallel to [010]. The former forms two hydrogen bonds with two carboxylate oxygen atoms from extended ligands in different sheets [N1...O9/O11, 2.808(5) and 2.883(5) $\AA$; N1$\mathrm{H} \cdots \mathrm{O} 9 / \mathrm{O} 11,155(5)$ and $\left.161(6)^{\circ}\right]$. More interestingly, the other cation is hydrogen bonded to three carboxylate groups (with one bifurcated bond) pertaining to two of the interpenetrated

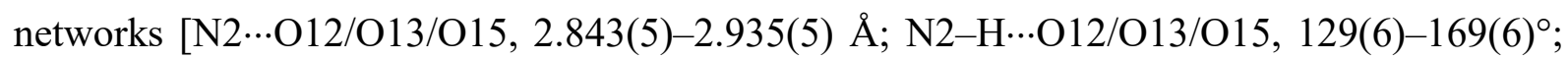
O12 and O15 pertain to the same network]. Examination of the HSs shows that both cations are further involved in $\mathrm{CH} \cdots \mathrm{O}$ interactions $\left[\mathrm{C} \cdots \mathrm{O}, 3.273(6)-3.463(6) \AA ̊ \AA \mathrm{C}-\mathrm{H} \cdots \mathrm{O}, 145-162^{\circ}\right]$, so that the intrasheet cation overall connects the three entangled networks. Thus, it is possible to consider as the core of a "monomer" unit used to form the threefold-interpenetrated polymer sheets one $\mathrm{H}_{2} \mathrm{NMe}_{2}{ }^{+}$cation and three attached polymer fragments which incorporate all the inequivalent uranium and ligand moieties. The KPI is 0.66 , some voids in the structure being occupied by unresolved solvent molecules (see Experimental Section). It is notable that the uranyl ion complex with muc ${ }^{2-}$ incorporating $\mathrm{H}_{2} \mathrm{NMe}_{2}{ }^{+}$cations, crystallized together with complex 2, displays quasi-planar hcb layers, but is not entangled (see above).

The counterpart of complex 5 with the muc ${ }^{2-}$ ligand, $\left[\left(\mathrm{UO}_{2}\right)_{3}(\mathrm{muc})_{2}(\mathrm{O})_{2} \mathrm{Cu}(R, S\right.$ $\mathrm{Me}_{6}$ cyclam)] (7), does not contain the formate anion, but it incorporates bridging oxido anions which generate a polynuclear secondary building unit (SBU). The three inequivalent uranium atoms are all in pentagonal-bipyramidal environments, but with different donors (Figure 7). U1 is bound to two carboxylate oxygen atoms from two muc ${ }^{2-}$ ligands and three oxido anions, U2 is bound to one chelating carboxylate group, one carboxylate oxygen atom from another ligand and two oxido anions, and U3 to one chelating carboxylate, two more carboxylate donors from different ligands and one oxido anion [U-O(uranyl), 1.783(6)-1.820(5) Å; U-O(carboxylato), 

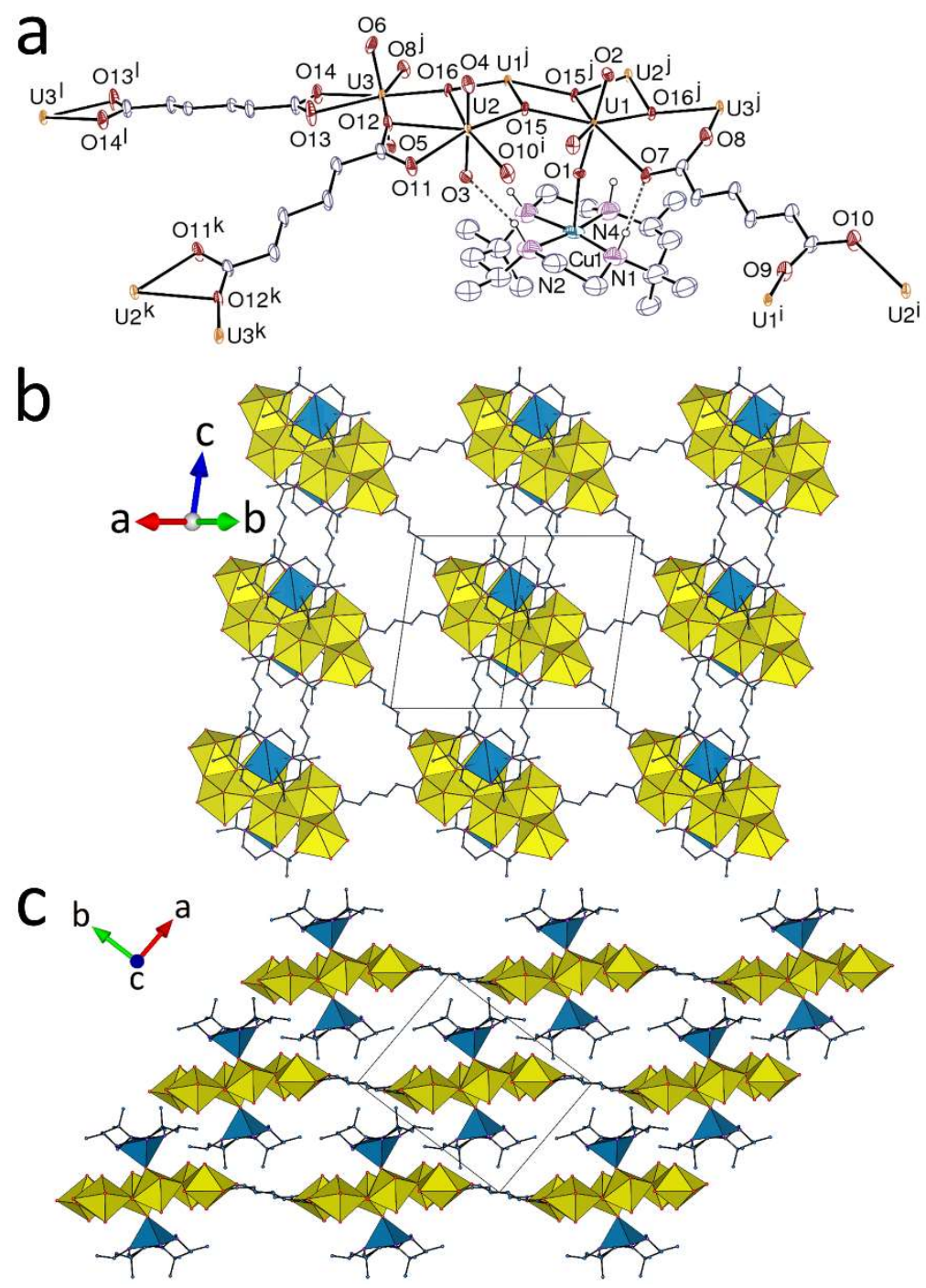

Figure 7. (a) View of compound 7. Displacement ellipsoids are drawn at the $30 \%$ probability level. Carbon-bound hydrogen atoms are omitted and hydrogen bonds are shown as dashed lines. Symmetry codes: $\mathrm{i}=1-x, 1-y,-z$; $\mathrm{j}=1-x, 1-y, 1-z ; \mathrm{k}=2-x,-y, 1-z ; 1=2-x,-y, 2-z$. (b) View of the diperiodic coordination polymer with uranium coordination polyhedra yellow and those of copper blue. (c) Packing with sheets viewed edge-on.

2.480(6)-2.531(4) $\AA$ for chelating groups, $2.330(5)-2.519(4) \AA$ for the others; $\mathrm{U}-\mathrm{O}\left(\mu_{3}-\mathrm{oxido}\right)$, 2.170(4)-2.290(4) $\AA$ ]. A quasi-planar, centrosymmetric, hexanuclear SBU is thus formed, which is held by four $\mu_{3}$-oxido anions and six bridging muc ${ }^{2-}$ ligands. Hexanuclear SBUs are not frequent in uranyl chemistry, ${ }^{17}$ and there is no exact equivalent of that found here. Another hexanuclear SBU has been generated with 2,4-pyridinedicarboxylate, but it contains a mixture of oxido and hydroxido ligands, and the polyhedra edge-sharing scheme is slightly different. ${ }^{60}$ 
The SBUs in 7 are assembled into a diperiodic network parallel to (110). If the hexanuclear moiety is considered as a single node, rows of doubly linked nodes (2-node loops) run along [001], which are further linked through four additional links between each node and four nodes in the adjoining rows. Overall, each SBU connects to six others, forming six triangular rings (disregarding 2-node loops), and the topological type is hxl (hexagonal). A notable feature of this structure is the axial bonding of $\mathrm{Cu}^{\mathrm{II}}$ to one uranyl oxo group, the metal environment being square pyramidal, with a $\mathrm{Cu}-\mathrm{O}$ bond length $[2.182(5) \AA]$ only slightly larger than those with the four macrocyclic nitrogen donors $[1.899(11)-2.120(12) \AA]$ and a $\mathrm{U}=\mathrm{O}-\mathrm{Cu}$ angle of $169.5(3)^{\circ}$. The $\mathrm{U}=\mathrm{O}$ bond involved is significantly lengthened, at $1.820(5) \AA$. Such uranyl oxobonding of $3 \mathrm{~d}$-block metal cations is rather frequent, and a case involving $\mathrm{Ni}(\text { cyclam })^{2+}$ with comparable $\mathrm{Ni}-\mathrm{O}$ and $\mathrm{U}=\mathrm{O}$ bond lengths of $2.189(4)$ and $1.814(4) \AA$, respectively, has recently been reported. ${ }^{61}$ The present $\mathrm{Cu}-\mathrm{O}$ bond length is however the shortest among the 13 cases involving $\mathrm{Cu}^{\mathrm{II}}$ reported in the CSD, the closest one being 2.266(4) $\AA .{ }^{62}$ Although badly resolved (see Experimental Section), the $R, S$-Me ${ }_{6}$ cyclam molecule appears to be in the $R S R S$ conformation, with the four amine protons directed on the same side and thus forming hydrogen bonds with uranyl oxo and carboxylato groups of the same diperiodic assembly $[\mathrm{N} \cdots \mathrm{O}$, 3.022(12)-3.255(13) $\left.\AA ; \mathrm{N}-\mathrm{H} \cdots \mathrm{O}, 141-175^{\circ}\right]$. Each SBU is bound to two inversion-related $\mathrm{Cu}\left(R, S-\mathrm{Me}_{6} \mathrm{cyclam}^{2+}\right.$ moieties, which are located on either side of the sheet and can be considered as mere decorating groups. These groups are protruding on both sides of the sheets and interdigitation governs the packing. The KPI of 0.57 indicates the presence of voids containing unresolved, disordered solvent molecules (see Experimental Section).

$\mathrm{PPh}_{3} \mathrm{Me}^{+}$is another cation for which complexes with both adp ${ }^{2-}$ and muc ${ }^{2-}$ ligands could be isolated, and the comparison of their structures is particularly interesting in view of entanglement formation. After complex 6, $\left[\mathrm{PPh}_{3} \mathrm{Me}_{2}\left[\left(\mathrm{UO}_{2}\right)_{2}(\mathrm{adp})_{3}\right] \cdot 4 \mathrm{H}_{2} \mathrm{O}(\mathbf{8})\right.$, shown in Figure 
8 , is another case in which both inequivalent uranium atoms are $\operatorname{tris}\left(\kappa^{2} O, O^{\prime}\right)$-chelated and thus in a hexagonal-bipyramidal environment [U-O(oxo), 1.772(5)-1.783(5) Å; U-O(carboxylato),

a

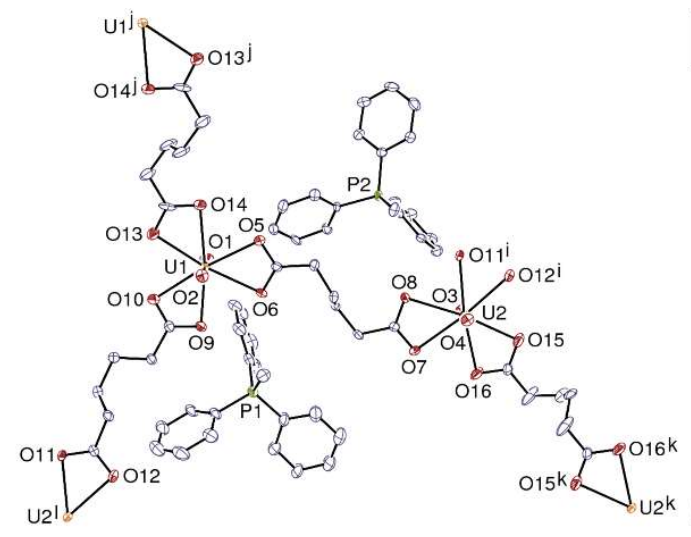

\section{C}

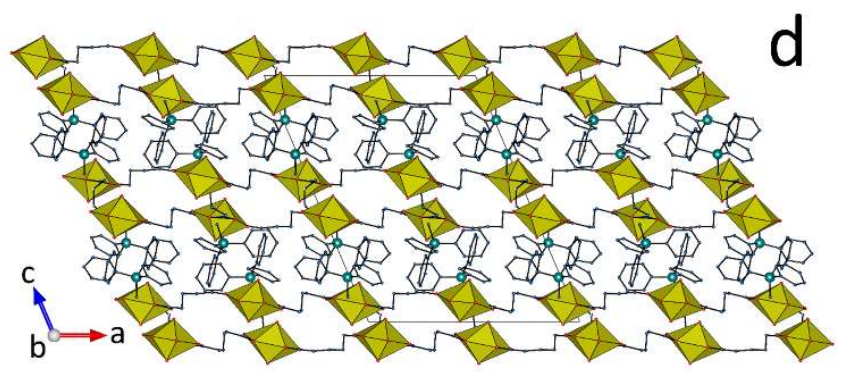

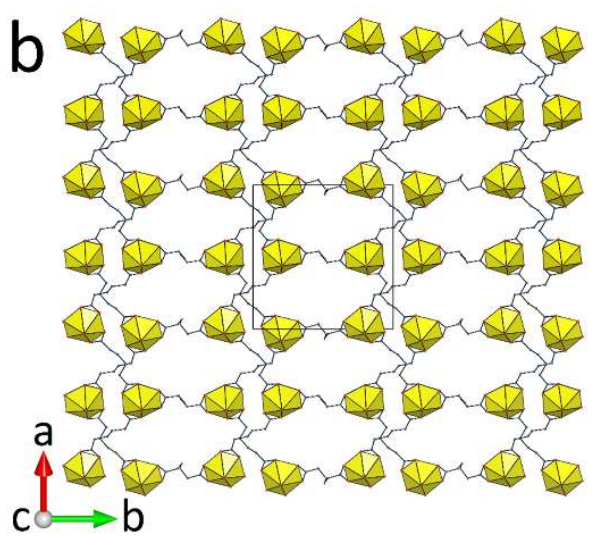

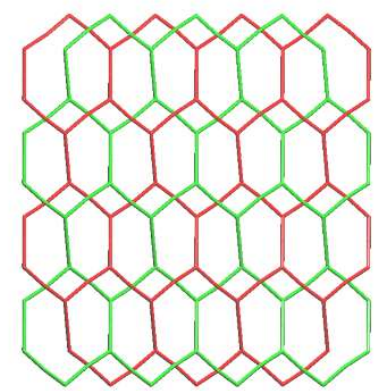

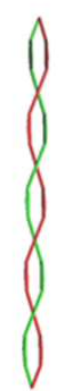

Figure 8. (a) View of compound 8. Displacement ellipsoids are drawn at the $50 \%$ probability level. Solvent molecules and hydrogen atoms are omitted. Only one position of the disordered parts is represented. Symmetry codes: $\mathrm{i}=x-1, y, z ; \mathrm{j}=1-x,-y, 1-z ; \mathrm{k}=-x, 2-y, 1-z ; 1=x+1, y, z$. (b) View of the twofold interpenetrated diperiodic networks. (c) Packing with sheets viewed edge-on. (d) Simplified view of the twofold interpenetration of diperiodic networks down [001] (left) or [100] (right).

2.440(5)-2.508(4) $\AA$ ], and two out of the four inequivalent $\operatorname{adp}^{2-}$ ligands are centrosymmetric. The diperiodic network formed, parallel to (001), has the hcb topology, but, although the four ligands are in curved or kinked conformations, giving the network an essentially undulating profile, it is less strongly corrugated than its counterpart in 6, with a maximum width of $\sim 7 \AA$, i.e. less than half that in $\mathbf{6}$. As a result, although parallel interpenetration occurs here also, it is only twofold, indicating a correlation between corrugation amplitude or layer thickness and degree of interpenetration which has also been found in the case of 2,5-thiophenedicarboxylate uranyl ion complexes ${ }^{35}$ (see discussion ahead). The anionic layers are separated by sheets of 
cations that, in terms of opposed orientations of the $\mathrm{P}-\mathrm{CH}_{3}$ bonds, can also be considered as double, while the water molecules all lie within the layers, no significant free space being left (KPI, 0.68 with disorder excluded). There is no indication of parallel $\pi$-stacking interactions, all centroid...centroid distances being larger than $5 \AA$. All P..P distances exceeding $8.5 \AA$, there is no significant "phenyl embrace" interaction either and the cations are mainly involved in $\mathrm{CH} \cdots \mathrm{O}$ weak bonding. One of the water molecules is hydrogen bonded to two carboxylate oxygen atoms pertaining to the two independent, entangled networks $[\mathrm{O} \cdots \mathrm{O}, 2.942(9)$ and 2.952(8) $\AA ; \mathrm{O}-\mathrm{H} \cdots \mathrm{O}, 157(11)$ and $\left.174(10)^{\circ}\right]$.

The counterpart of complex $\mathbf{8}$ involving the muc ${ }^{2-}$ ligand, $\left[\mathrm{PPh}_{3} \mathrm{Me}\right]_{2}\left[\left(\mathrm{UO}_{2}\right)_{2}(\mathrm{muc})_{3}\right] \cdot \mathrm{H}_{2} \mathrm{O}(9)$, displays also the same tris $\left(\kappa^{2} O, O^{\prime}\right)$-chelation of the uranyl cation [U-O(oxo), 1.7791(18) and 1.7794(19) Å; U-O(carboxylato), 2.4094(17)-2.5061(19) $\AA$ ], and a diperiodic network of hcb topology is also formed (Figure 9). However, as in complex $\mathbf{2}$, the rigid, quasi-planar shape of the ligand results in the coordination polymer being itself quasi-planar, and as a result not well adapted to parallel interpenetration. Twofold $2 \mathrm{D}+2 \mathrm{D} \rightarrow$ 3D inclined polycatenation is found instead, the two families of layers being parallel to (102) or (102) and having [010] as zone direction, with an angle of $69.4^{\circ}$ between the two families of planes (Figure 10). The hexanuclear rings are oblong in shape, with approximate edge dimensions of 23 and $12 \AA$, and they are arranged in herringbone fashion. These large size and elongated shape allow for each hexanuclear ring to be crossed by two layers from the inclined family of planes, the degree of catenation ${ }^{3}$ being thus 2 , and one uranyl cation from each of these two layers is located inside the ring. Channels with a roughly rhombus-shaped section with diagonal lengths of $\sim 12$ and $6 \AA$ are running along the zone direction, in which the counterions are arranged in rows. With a P...P distance of 8.5771(4) $\AA$ within the rows, the $\mathrm{PPh}_{3} \mathrm{Me}^{+}$counterions are not involved in strong interactions with one another, there being no 

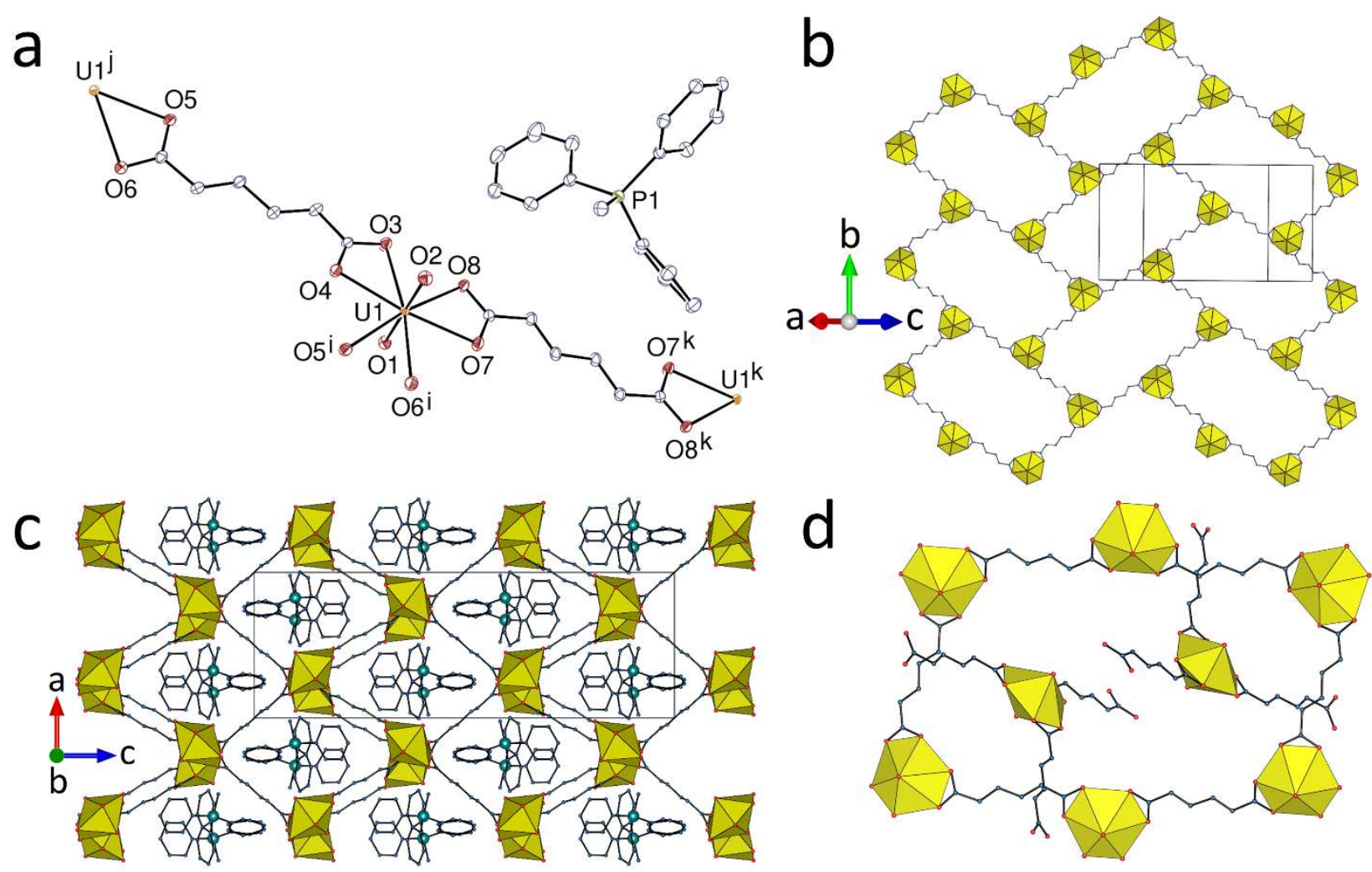

Figure 9. (a) View of compound 9. Displacement ellipsoids are drawn at the 50\% probability level. Solvent molecules and hydrogen atoms are omitted. Symmetry codes: $\mathrm{i}=1-x, y-1 / 2,1 / 2-z ; \mathrm{j}=1-x, y+1 / 2,1 / 2-z$; $\mathrm{k}=2-x,-y, 1-z$. (b) View of the hcb diperiodic network. (c) View of the polycatenated structure with sheets edge-on. (d) View of one hexanuclear ring with the two included uranyl cations pertaining to the two intersecting planes.

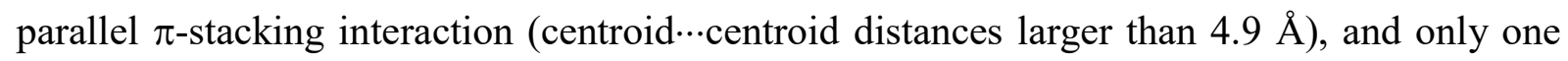
possible orthogonal $\mathrm{CH} \cdots \pi$ interaction $\left[\mathrm{H} \cdots\right.$ centroid, $2.74 \AA$; $\mathrm{C}-\mathrm{H} \cdots$ centroid, $\left.159^{\circ}\right]$. However, this interaction does not appear conspicuously on the HS which, as usual, reveals numerous $\mathrm{CH} \cdots \mathrm{O}$ hydrogen bonds involving hydrogen atoms from both the methyl group and the aromatic rings and, most importantly, carboxylate groups from the two families of intersecting planes. Overall, with a KPI of 0.69 , the packing is quite compact. 


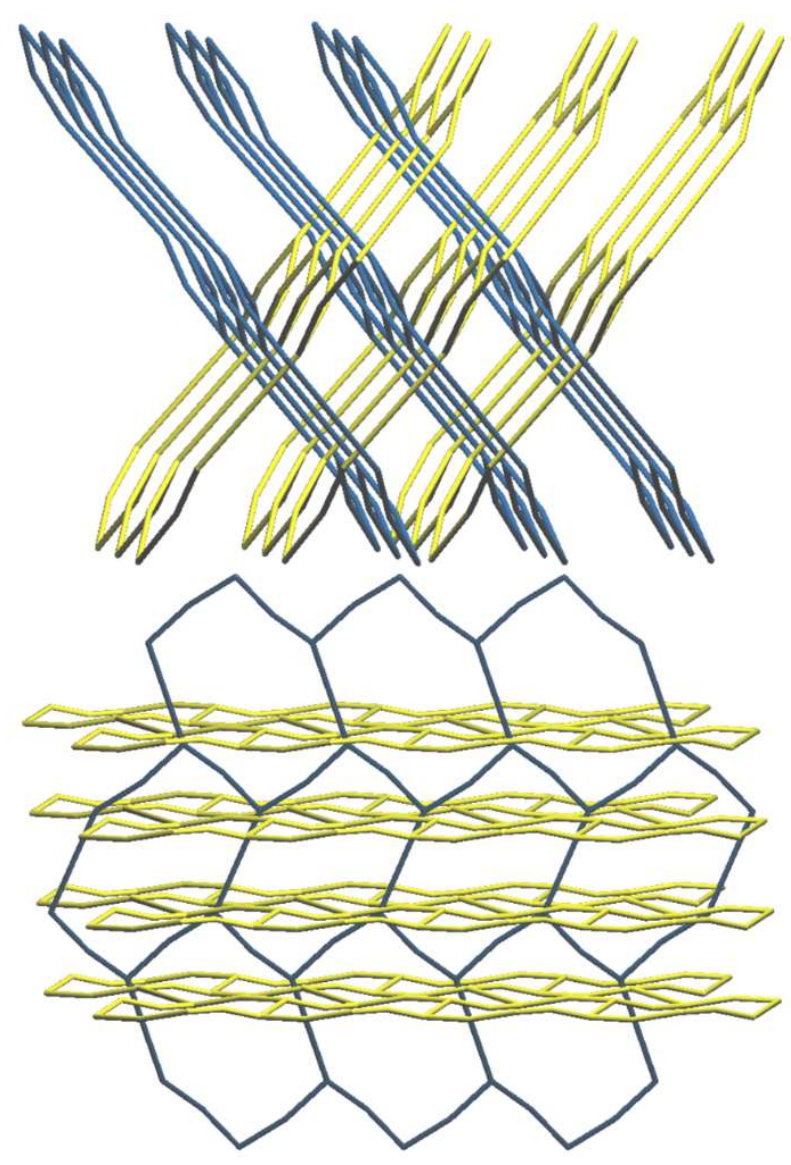

Figure 10. Two views of the simplified representation of the twofold polycatenation of diperiodic networks in complex 9, slightly rotated from the zone direction (top), and showing the double crossing of each hexagonal ring (bottom).

For a discussion of these entangled structures, it is convenient to separate the topological/geometrical viewpoint, which is related to the possibility of their formation and the nature of the possible entanglements, and the consideration of weak interactions with counterions or solvent molecules, which may exert a structure-directing role during the formation of the entangled species (of course, such a separation is somewhat arbitrary since the topology and shape of the network may also depend in part on the structure-directing species). The three entangled species described here involve diperiodic networks of hcb topology, the second most common topology (after sql) found in diperiodic entanglements. ${ }^{5}$ Out of the five hcb networks found in this work (complexes 1, 2, 6, 8 and 9, i.e. all the anionic homometallic complexes), three display entanglement, the nature of which appears to be governed by the 
shape of the layers. As shown in Figure 11, the gently undulating individual network in complex 8 and the sawtooth-shaped one in $\mathbf{6}$ are associated with twofold and threefold parallel interpenetration, respectively. The shape of the layers seems to be more important here than the size of the hexanuclear rings since the transannular distances between uranium atoms are not widely different [15.1721(13), 19.4689(14) and 24.4327(14) $\AA$ in 6; 19.2646(9), 22.0081(11)

9

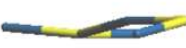

8

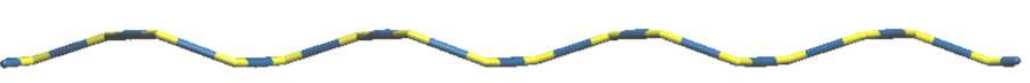

6

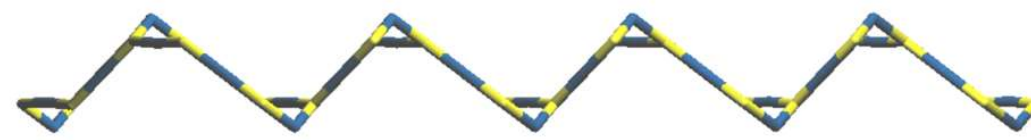

Inclined Polycatenation

Twofold Parallel
Interpenetration

Threefold Parallel Interpenetration

Figure 11. Edge-on views of hcb networks (individual networks and not the entangled assemblies) in 6 (down [11̄0]), 8 (down [100]), and $\mathbf{9}$ (down [010]), with uranium nodes yellow and dicarboxylate links blue, and nature of the associated entanglement.

and 22.8423(11) $\AA$ in 8]. It is known that thick diperiodic layers are prone to give $2 \mathrm{D} \rightarrow 3 \mathrm{D}$ parallel polycatenation, ${ }^{2,5}$ and this has been observed with highly corrugated layers of hcb topology in the case of a copper complex. ${ }^{63}$ However, in the present family of aliphatic $\alpha, \omega-$ dicarboxylate uranyl ion complexes, this has only been found to occur with extremely convoluted layers with the vertex symbol $\left\{8^{2} .10\right\}$ involving the pimelate ligand. ${ }^{26,27}$ At the opposite, quasi-planarity of layers when a ligand as flexible as adp ${ }^{2-}$ is involved can be achieved through introduction of a rigid, linear and divergent coligand, as in $\left[\mathrm{UO}_{2}(\operatorname{adp})\left(4,4^{\prime}\right.\right.$-bipy $\left.)\right],{ }^{21}$ in which the layers, with sql topology, are associated through threefold inclined polycatenation. It can also be attained through stiffening the dicarboxylate ligand itself into an elongated conformation, the simplest modification for that being the introduction of double bonds as 
found in $\mathrm{muc}^{2-}$. In this case, the hcb topology is retained and twofold inclined polycatenation ensues, with hexanuclear rings sufficiently large [transannular U...U distances, 16.7844(9), $23.6437(10)$ and $26.8951(13) \AA]$ to allow for a degree of catenation of 2 (a larger value of 4 is found for the larger rings in uranyl complexes with 4,4'-biphenyldicarboxylate ${ }^{64}$ ). Overall, the pattern is similar to that recently described for 2,5-thiophenedicarboxylate, ${ }^{35}$ except that in this case the variation of the shape does not arise from the flexibility of the linkers, but from tilting of the nearly planar ligands out of the uranyl equatorial plane.

While hcb networks are also formed in complexes $\mathbf{1}$ and $\mathbf{2}$, in contrast to complexes $\mathbf{6}$, 8 and 9 no entanglement is present in these cases, which is most probably attributable to the different structure-directing effects of the counterions and solvent molecules, which are in a large measure unpredictable. ${ }^{65}$ In particular, complexes $\mathbf{1}$ and $\mathbf{8}$ contain the closely related counterions $\mathrm{PPh}_{4}{ }^{+}$and $\mathrm{PPh}_{3} \mathrm{Me}^{+}$, and the hcb network in $\mathbf{1}$ would appear to be adequately corrugated for twofold or even threefold interpenetration to occur; it may be surmised that it is prevented in this case by the stacking preferences of the counterions. At least, it appears that the strong tendency exhibited by the uranyl ion to form quasi-planar, undulated or corrugated diperiodic, graphite-like ${ }^{66}$ networks when complexed by divergent dicarboxylates is an auspicious trend in view of obtaining entangled species, particularly when the ligands are sufficiently elongated to form large rings. The formation of entangled species is a complicated phenomenon which displays some unexpected features probably associated with the lability of the metal-ligand coordinate bond, such as partial ${ }^{67}$ or reversible ${ }^{68}$ interpenetration, or singlecrystal to single-crystal transformations involving a change in interpenetration degree ${ }^{69}$ for example. The fullfilment of the possibilities of entanglement offered by a network on purely geometrical grounds depends on subtle interactions between the different components, solvents and counterions. In the present cases of complexes $\mathbf{6}$ and $\mathbf{9}$, it is notable that each counterion is involved in weak interactions with the different diperiodic components of the entanglement, 
thus suggesting that the formation could possibly proceed from small aggregates of these components organized around the cations. However, given the lability of the species involved, the process could well be much more complicated.

\section{CONCLUSIONS}

Adipate and trans,trans-muconate are two ligands of similar length differing essentially by the former being a highly flexible species while the latter is rigid and quasi-planar, a difference which has conspicuous effects on the crystal structure of their uranyl ion complexes. In the case of the heterometallic complexes containing $\mathrm{Ni}(\text { cyclam })^{2+}$ or $\mathrm{Cu}\left(R, S-\mathrm{Me}_{6} \mathrm{cyclam}\right)^{2+}$ moieties, those involving adp ${ }^{2-}$ are diperiodic species with simple topologies, while those with muc ${ }^{2-}$ are either a triperiodic framework or a diperiodic network based on a hexanuclear secondary building unit. In these cases, although it is apparent, the effect of the difference between the two ligands is not easily rationalized. All the other complexes, with phosphonium, dimethylammonium or $\left[\mathrm{Ni}(\text { bipy })_{3}\right]^{2+}$ counterions, crystallize as diperiodic networks with the same hcb topology involving uranium nodes and dicarboxylate links, and there the effects of ligand flexibility are most apparent. The ability of the adp ${ }^{2-}$ aliphatic chain to adopt different conformations, from regularly extended to various twisted or kinked forms allows for two different layer geometries being adopted with $\mathrm{PPh}_{3} \mathrm{Me}^{+}$or $\mathrm{H}_{2} \mathrm{NMe}_{2}{ }^{+}$counterions, with profiles either gently undulated or square-waved, resulting in different degrees of interpenetration, twofold in $\mathbf{8}$ and threefold in $\mathbf{6}$. In contrast, the near-planarity of the muc ${ }^{2-}$ ligand and of the network formed in 9 allows only for twofold inclined polycatenation. These results show that, in this system, ligand rigidity is not an essential requirement for entanglement, although its actual form depends upon the deviation of the polymer array from planarity, an aspect which is determined by the balance between rotational barriers and other weak interactions, notably hydrogen bonding. Exactly how entanglement may arise is an intriguing question. In the three 
present examples, what does distinguish them from the non-entangled structures is that an analysis of weak interactions can be used to define small aggregates of the inequivalent crystal components which could interact in a way in which the formally independent coordination polymer chains would grow simultaneously.

\section{ASSOCIATED CONTENT}

\section{Accession Codes}

CCDC 2113749-2113757 contain the supplementary crystallographic data for this paper. These data can be obtained free of charge via www.ccdc.cam.ac.uk/data_request/cif, or by emailing data_request@ccdc.cam.ac.uk, or by contacting The Cambridge Crystallographic Data Centre, 12 Union Road, Cambridge CB2 1EZ, UK; fax: +44 1223336033.

\section{AUTHOR INFORMATION}

\section{Corresponding Authors}

*E-mail: pierre.thuery@cea.fr. (P.T.)

*E-mail: harrowfield@unistra.fr. (J.H.)

\section{ORCID}

Pierre Thuéry: 0000-0003-1683-570X

Jack Harrowfield: 0000-0003-4005-740X

\section{Notes}

The authors declare no competing financial interest. 


\section{REFERENCES}

1. Batten, S. R.; Robson, R. Interpenetrating Nets: Ordered, Periodic Entanglement. Angew. Chem. Int. Ed. 1998, 37, 1460-1494.

2. Batten, S. R. Topology of Interpenetration. CrystEngComm 2001, 3, 67-72.

3. Carlucci, L.; Ciani, G.; Proserpio, D. M. Polycatenation, Polythreading and Polyknotting in Coordination Network Chemistry. Coord. Chem. Rev. 2003, 246, 247-289.

4. Blatov, V. A.; Carlucci, L.; Ciani, G.; Proserpio, D. M. Interpenetrating Metal-Organic and Inorganic 3D Networks: a Computer-Aided Systematic Investigation. Part I. Analysis of the Cambridge Structural Database. CrystEngComm 2004, 6, 377-395.

5. Carlucci, L.; Ciani, G.; Proserpio, D. M.; Mitina, T. G.; Blatov, V. A. Entangled TwoDimensional Coordination Networks: A General Survey. Chem. Rev. 2014, 114, $7557-7580$.

6. Alexandrov, E. V.; Blatov, V. A.; Proserpio, D. M. How 2-Periodic Coordination Networks are Interweaved: Entanglement Isomerism and Polymorphism. CrystEngComm 2017, 19, 1993-2006.

7. Jiang, H. L.; Makal, T. A.; Zhou, H. C. Interpenetration Control in Metal-Organic Frameworks for Functional Applications. Coord. Chem. Rev. 2013, 257, 2232-2249.

8. Yang, G. P.; Hou, L.; Ma, L. F.; Wang, Y. Y. Investigation on the Prime Factors Influencing the Formation of Entangled Metal-Organic Frameworks. CrystEngComm 2013, 15, 25612578.

9. Haldar, R.; Sikdar, N.; Maji, T. K. Interpenetration in Coordination Polymers: Structural Diversities toward Porous Functional Materials. Mater. Today 2015, 18, 97-116. 
10. Gong, Y. N.; Zhong, D. C.; Lu, T. B. Interpenetrating Metal-Organic Frameworks. CrystEngComm 2016, 18, 2596-2606.

11. Gupta, M.; Vittal, J. J. Control of Interpenetration and Structural Transformations in the Interpenetrated MOFs. Coord. Chem. Rev. 2021, 435, 213789.

12. Lehn, J. M. Dynamers: Molecular and Supramolecular Polymers. Aust. J. Chem. 2005, 63, 814-831.

13. Dobrawa, R.; Würthner, F. Metallosupramolecular Approach toward Functional Coordination Polymers. J. Polymer Sci. A. Polymer Chem. 2005, 43, 4981-4995.

14. Delgado-Friedrichs, O.; Foster, M. D.; O’Keeffe, M.; Proserpio, D. M.; Treacy, M. M. J.; Yaghi, O.M. What do we Know about Three-Periodic Nets ? J. Solid State Chem. 2005, $178,2533-2554$.

15. Wang, K. X.; Chen, J. S. Extended Structures and Physicochemical Properties of UranylOrganic Compounds. Acc. Chem. Res. 2011, 44, 531-540.

16. Andrews, M. B.; Cahill, C. L. Uranyl Bearing Hybrid Materials: Synthesis, Speciation, and Solid-State Structures. Chem. Rev. 2013, 113, 1121-1136.

17. Loiseau, T.; Mihalcea, I.; Henry, N.; Volkringer, C. The Crystal Chemistry of Uranium Carboxylates. Coord. Chem. Rev. 2014, 266-267, 69-109.

18. Su, J.; Chen, J. S. MOFs of Uranium and the Actinides. Struct. Bond. 2015, 163, 265-296.

19. Thuéry, P.; Harrowfield, J. Recent Advances in Structural Studies of Heterometallic Uranyl-Containing Coordination Polymers and Polynuclear Closed Species. Dalton Trans. 2017, 46, 13660-13667.

20. Lv, K.; Fichter, S.; Gu, M.; März, J.; Schmidt, M. An Updated Status and Trends in Actinide Metal-Organic Frameworks (An-MOFs): From Synthesis to Application. Coord. Chem. Rev. 2021, 446, 214011. 
21. Borkowski, L. A.; Cahill, C. L. Crystal Engineering with the Uranyl Cation II. Mixed Aliphatic Carboxylate/Aromatic Pyridyl Coordination Polymers: Synthesis, Crystal Structures, and Sensitized Luminescence. Cryst. Growth Des. 2006, 6, 2248-2259.

22. Groom, C. R.; Bruno, I. J.; Lightfoot, M. P.; Ward, S. C. The Cambridge Structural Database. Acta Crystallogr., Sect. B 2016, 72, 171-179.

23. Taylor, R.; Wood, P. A. A Million Crystal Structures: The Whole is Greater than the Sum of Its Parts. Chem. Rev. 2019, 119, 9427-9477.

24. Borkowski, L. A.; Cahill, C. L. Topological Evolution in Uranyl Dicarboxylates: Synthesis and Structures of One-Dimensional $\mathrm{UO}_{2}\left(\mathrm{C}_{6} \mathrm{H}_{8} \mathrm{O}_{4}\right)\left(\mathrm{H}_{2} \mathrm{O}\right)_{2}$ and Three-Dimensional $\mathrm{UO}_{2}\left(\mathrm{C}_{6} \mathrm{H}_{8} \mathrm{O}_{4}\right)$. Inorg. Chem. 2003, 42, 7041-7045.

25. Thuéry, P.; Harrowfield, J. A New Form of Triple-Stranded Helicate Found in Uranyl Complexes of Aliphatic $\alpha, \omega$-Dicarboxylates. Inorg. Chem. 2015, 54, 10539-10541.

26. Thuéry, P.; Rivière, E.; Harrowfield, J. Counterion-Induced Variations in the Dimensionality and Topology of Uranyl Pimelate Complexes. Cryst. Growth Des. 2016, $16,2826-2835$.

27. Thuéry, P.; Atoini, Y.; Harrowfield, J. Structure-Directing Effects of Counterions in Uranyl Ion Complexes with Long-Chain Aliphatic $\alpha, \omega$-Dicarboxylates: 1D to Polycatenated 3D Species. Inorg. Chem. 2019, 58, 567-580.

28. Thuéry, P. From Helicates to Borromean Links: Chain Length Effect in Uranyl Ion Complexes of Aliphatic $\alpha, \omega$-Dicarboxylates. Cryst. Growth Des. 2016, 16, 546-549.

29. Hu, K. Q.; Jiang, X.; Wang, C. Z.; Mei, L.; Xie, Z. N.; Tao, W. Q.; Zhang, X. L.; Chai, Z. F.; Shi, W. Q. Solvent-Dependent Synthesis of Porous Anionic Uranyl-Organic Frameworks Featuring a Highly Symmetrical $(3,4)$-Connected ctn or bor Topology for Selective Dye Adsorption. Chem. Eur. J. 2017, 23, 529-532. 
30. Liu, C.; Chen, F. Y.; Tian, H. R.; Ai, J.; Yang, W.; Pan, Q. J.; Sun, Z. M. Interpenetrated Uranyl-Organic Frameworks with bor and pts Topology: Structure, Spectroscopy, and Computation. Inorg. Chem. 2017, 56, 14147-14156.

31. Wang, S.; Mei, L.; Yu, J. P.; Hu, K. Q.; Liu, Z. R.; Chai, Z. F.; Shi, W. Q. Large-Pore Layered Networks, Polycatenated Frameworks, and Three-Dimensional Frameworks of Uranyl Tri(biphenyl)amine/Tri(phenyl)amine Tricarboxylate: Solvent-/Ligand-Dependent Dual Regulation. Cryst. Growth Des. 2018, 18, 4347-4356.

32. Liang, L. L.; Zhang, R. L.; Zhao, J. S. Counterion-Controlled Formation of Layered Honeycomb and Polythreading Uranyl Networks and the Highly Sensitive and Selective Detection of $\mathrm{Fe}^{3+}$ in Aqueous Media. Inorg. Chem. 2020, 59, 7980-7990.

33. Surbella, R. G., III, Carter, K. P.; Lohrey, T. D.; Reilly, D.; Kalaj, M.; McNamara, B. K.; Schwantes, J.; Abergel, R. J. Rational Design of a Uranyl Metal-Organic Framework for the Capture and Colorimetric Detection of Organic Dyes. Chem. Eur. J. 2020, 26, 1381913825.

34. Hou, X.; Tang, S. F. Variability of Uranyl Carboxylates from Rigid Terophenyldicarboxylic Acid Ligands. Inorg. Chem. 2020, 59, 15824-15831.

35. Thuéry, P.; Harrowfield, J. 2,5-Thiophenedicarboxylate: An Interpenetration-Inducing Ligand in Uranyl Chemistry. Inorg. Chem. 2021, 60, 9074-9083.

36. Thuéry, P.; Harrowfield, J. $[\mathrm{Ni}(\text { cyclam })]^{2+}$ and $\left[\mathrm{Ni}\left(R, S-\mathrm{Me}_{6} \text { cyclam }\right)\right]^{2+}$ as Linkers or Counterions In Uranyl-Organic Species with cis- and trans-1,2-Cyclohexanedicarboxylate Ligands. Cryst. Growth Des. 2018, 18, 5512-5520.

37. APEX3 Crystallography Software Suite, Ver. 2019.1-0; Bruker AXS: Madison, WI, USA, 2019.

38. Hooft, R. W. W. COLLECT, Nonius BV: Delft, The Netherlands, 1998. 
39. Otwinowski, Z.; Minor, W. Processing of X-Ray Diffraction Data Collected in Oscillation Mode. Methods Enzymol. 1997, 276, 307-326.

40. SAINT, Ver. 8.40A; Bruker Nano: Madison, WI, USA, 2019.

41. SADABS, Bruker/Siemens Area Detector Absorption and Other Corrections, Ver. 2016/2; Bruker AXS: Madison, WI, USA, 2016.

42. Krause, L.; Herbst-Irmer, R.; Sheldrick, G. M.; Stalke, D. Comparison of Silver and Molybdenum Microfocus X-Ray Sources for Single-Crystal Structure Determination. $J$. Appl. Crystallogr. 2015, 48, 3-10.

43. Sheldrick, G. M. SHELXT - Integrated Space-Group and Crystal-Structure Determination. Acta Crystallogr., Sect. A 2015, 71, 3-8.

44. Sheldrick, G. M. Crystal Structure Refinement with SHELXL. Acta Crystallogr., Sect. C 2015, 71, 3-8.

45. Hübschle, C. B.; Sheldrick, G. M.; Dittrich, B. ShelXle: a Qt Graphical User Interface for SHELXL. J. Appl. Crystallogr. 2011, 44, 1281-1284.

46. Spek, A. L. PLATON SQUEEZE: a Tool for the Calculation of the Disordered Solvent Contribution to the Calculated Structure Factors. Acta Crystallogr., Sect. C 2015, 71, 9-18.

47. Farrugia, L. J. WinGX and ORTEP for Windows: an Update. J. Appl. Crystallogr. 2012, $45,849-854$.

48. Momma, K.; Izumi, F. VESTA 3 for Three-Dimensional Visualization of Crystal, Volumetric and Morphology Data. J. Appl. Crystallogr. 2011, 44, 1272-1276.

49. Blatov V. A.; Shevchenko, A. P.; Proserpio, D. M. Applied Topological Analysis of Crystal Structures with the Program Package ToposPro. Cryst. Growth Des. 2014, 14, 3576-3586.

50. Spek, A. L. Structure Validation in Chemical Crystallography. Acta Crystallogr., Sect. D 2009, 65, 148-155. 
51. Dance, I.; Scudder, M. Supramolecular Motifs: Concerted Multiple Phenyl Embraces between $\mathrm{Ph}_{4} \mathrm{P}^{+}$Cations are Attractive and Ubiquitous. Chem. Eur. J. 1996, 2, 481-486.

52. Taylor, R.; Kennard, O. Crystallographic Evidence for the Existence of C-H $\cdots \mathrm{O}, \mathrm{C}-\mathrm{H} \cdots \mathrm{N}$, and C-H...Cl Hydrogen Bonds. J. Am. Chem. Soc. 1982, 104, 5063-5070.

53. Desiraju, G. R. The C-H‥O Hydrogen Bond: Structural Implications and Supramolecular Design. Acc. Chem. Res. 1996, 29, 441-449.

54. Thuéry, P.; Harrowfield, J. Uranyl Ion Complexes with Long-Chain Aliphatic $\alpha, \omega-$ Dicarboxylates and 3d-Block Metal Counterions. Inorg. Chem. 2016, 55, 2133-2145.

55. Spackman, M. A.; Jayatilaka, D. Hirshfeld Surface Analysis. CrystEngComm 2009, 11, 19 32.

56. Wolff, S. K.; Grimwood, D. J.; McKinnon, J. J.; Turner, M. J.; Jayatilaka, D.; Spackman, M. A. CrystalExplorer, University of Western Australia, 2012.

57. Thuéry, P.; Atoini, Y.; Harrowfield, J. 1,2-, 1,3-, and 1,4-Phenylenediacetate Complexes of the Uranyl Ion with Additional Metal Cations and/or Ancillary N-Donor Ligands: Confronting Ligand Geometrical Proclivities. Cryst. Growth Des. 2019, 19, 6611-6626.

58. Thuéry, P.; Atoini, Y.; Harrowfield, J. 1,3-Adamantanedicarboxylate and 1,3Adamantanediacetate as Uranyl Ion Linkers: Effect of Counterions, Solvents and Differences in Flexibility. Eur. J. Inorg. Chem. 2019, 4440-4449.

59. Su, C. Y.; Smith, M. D.; Goforth, A. M.; zur Loye, H. C. A Three-Dimensional, Noninterpenetrating Metal-Organic Framework with the Moganite Topology: A Simple $\left(4^{2} .6^{2} .8^{2}\right)\left(4.6^{4} .8\right)_{2}$ Net Containing Two Kinds of Topologically Nonequivalent Points. Inorg. Chem. 2004, 43, 6881-6883.

60. Zheng, Y. Z.; Tong, M. L.; Chen, X. M. Synthesis, Structure and Photoluminescent Studies of Two Novel Layered Uranium Coordination Polymers Constructed from $\mathrm{UO}(\mathrm{OH})$ Polyhedra and Pyridinedicarboxylates. Eur. J. Inorg. Chem. 2005, 4109-4117. 
61. Thuéry, P.; Harrowfield, J. Contrasting Structure-Directing Effects in the UranylPhthalate/Isophthalate Isomer Systems. Cryst. Growth Des. 2021, 21, 3000-3013.

62. Kerr, A. T.; Ridenour, J. A.; Noring, A. A.; Cahill, C. L. Two Uranyl-Copper(II) Bimetallic Coordination Polymers Containing trans-3,3(pyridyl)acrylic acid: Structural Variance through Synthetic Subtleties. Inorg. Chim. Acta 2019, 494, 204-210.

63. Zhang, X. M.; Chen, X. M. A New Porous 3-D Framework Constructed From Fivefold Parallel Interpenetration of 2-D (6,3) Nets: A Mixed-Valence Copper(I,II) Coordination Polymer $\left[\mathrm{Cu}_{2}^{\mathrm{I}} \mathrm{Cu}^{\mathrm{II}}\left(4,4^{\prime}-\text { bpy }\right)_{2}(\text { pydc })_{2}\right] \cdot 4 \mathrm{H}_{2} \mathrm{O}$. Eur. J. Inorg. Chem. 2003, 413-417.

64. Thuéry, P.; Harrowfield, J. Structural Variations in the Uranyl/4,4'-Biphenyldicarboxylate System. Rare Examples of 2D $\rightarrow$ 3D Polycatenated Uranyl-Organic Networks. Inorg. Chem. 2015, 54, 8093-8102.

65. Batten, S. R. Glorious Uncertainty - Challenges for Network Design. J. Solid State Chem. 2005, 178, 2475-2479.

66. Serezhkin, V. N.; Grigoriev, M. S.; Rogaleva, E. F.; Novikov, S. A.; Serezhkina, L. B. Isoreticular 2D Uranyl Coordination Polymers Based on the Mixed Oxalate-Succinate Linkers. Solid State Sci. 2021, 112, 106531.

67. Ferguson, A.; Liu, L.; Tapperwijn, S. J.; Perl, D.; Coudert, F. X.; Van Cleuvenbergen, S.; Verbiest, T.; van der Veen, M. A.; Telfer, S. G. Controlled Partial Interpenetration in MetalOrganic Frameworks. Nature Chem. 2016, 8, 250-257.

68. Choi, S. B.; Furukawa, H.; Nam, H. J.; Jung, D. Y.; Jhon, Y. H.; Walton, A.; Book, D.; O’Keeffe, M.; Yaghi, O. M.; Kim, J. Reversible Interpenetration in a Metal-Organic Framework Triggered by Ligand Removal and Addition. Angew. Chem. Int. Ed. 2012, 51, $8791-8795$. 
69. Aggarwal, H.; Bhatt, P. M.; Bezuidenhout, C. X.; Barbour, L. J. Direct Evidence for SingleCrystal to Single-Crystal Switching of Degree of Interpenetration in a Metal-Organic Framework. J. Am. Chem. Soc. 2014, 136, 3776-3779. 
For Table of Contents Use Only

\section{Contrasting Networks and Entanglements in Uranyl Ion Complexes with Adipic and trans,trans-Muconic Acids}

Pierre Thuéry and Jack Harrowfield

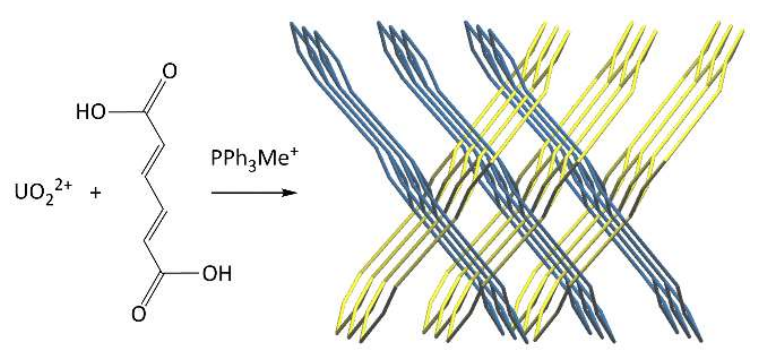

The difference in flexibility of adipate and muconate results in structural differences in their uranyl ion complexes incorporating diverse structure-directing agents, the most notable case being the switch from twofold parallel interpenetration to $2 \mathrm{D} \rightarrow 3 \mathrm{D}$ inclined polycatenation with the $\mathrm{PPh}_{3} \mathrm{Me}^{+}$counterion. 